\title{
EUROPÄISCHE UNION, GLOBALISIERUNG und HANSE
}

\author{
ÜBERLEGUNGEN ZUR AKTUELLEN VEREINNAHMUNG \\ EINES HISTORISCHEN PHÄNOMENS
}

von Rolf Hammel-Kiesow

\section{Einleitung}

Die Hanse hat zu Beginn des 21. Jahrhunderts ganz offensichtlich Konjunktur. Nachdem sie in den letzten Jahrzehnten des 20. Jahrhunderts fast nur noch für Fachleute, die sich professionell mit der Vergangenheit befassten, und für Einwohner vor allem kleinerer Hansestädte interessant zu sein schien, findet sie in den Medien und in der Öffentlichkeit nun wieder zunehmend Beachtung. Auslöser des wiedererwachten Interesses war in erster Linie die Intensivierung der Kontakte der Ostseeanrainerstaaten untereinander und mit den Staaten des übrigen Europa seit Anfang der 1990er Jahre. Sie wurde und wird häufig mit dem Namen der Hanse in Verbindung gebracht.

Der Ostseeraum ist wegen der großen Zahl internationaler Organisationen, die dort nach der Auflösung und Umwandlung der drei politischen Blöcke und ihrer Wirtschaftsorganisationen' tätig sind, eine oft zitierte Modellregion: Anfang der 1990er Jahre wurde diese Modellregion als „Neue Hanse“ ausgerufen, als Laboratorium Europas bezeichnet, zum Nukleus Europas erklärt. ${ }^{2}$ Gleichzeitig begann eine Folge weiterer positi-

\footnotetext{
' Der EFTA (European Free Trade Association) der blockfreien Staaten, der EWG (Europäische Wirtschaftsgemeinschaft) als Wirtschaftsverband der europäischen NATO-Staaten und des COMECON (Council for Mutual Economic Assistance), des Rates für gegenseitige Wirtschaftshilfe der Warschauer Pakt-Staaten.

${ }^{2}$ Die Internet-Suche nach den Stichworten „Ostseeraum/Wirtschaft/Entwicklung“ ergibt Tausende von Adressen, u. a. das „Baltic Sea Portal - Your Gateway to the Baltic Sea Region“. Uber dieses Portal gelangt man zu 13 internationalen und auf den Ostseeraum bezogenen Organisationen, beginnend mit dem "Council of the Baltic Sea States", über das „Baltic Development Center" bis zur „Union of the Baltic Cities“, eine kontinuierlich wachsende Organisation mit derzeit 100 Mitgliedsstädten in allen zehn Ostseeanrainerstaaten. Es gibt allerdings auch eine 1991 gegründete ,Neue Hanse Interregio' im Westen, in der Niedersachsen, die Freie Hansestadt Bremen und die niederländischen Provinzen Drenthe, Friesland, Groningen und Overijssel ,interregional-grenzüberschreitend“ zusammenarbeiten.
} 
ver Konnotationen des Begriffs Hanse: Die Städte Wismar, Rostock, Stralsund, Greifswald, Anklam und Demmin nahmen nach 1989 die Bezeichnung „Hansestadt“ in ihren offiziellen Stadtnamen auf, die erstge-

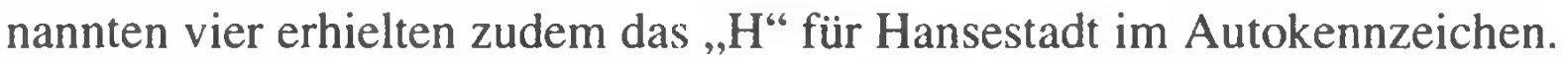
Auch gegenwärtig gibt es gleichgcrichtcte Versuche anderer ehemaliger Hansestädte, z. B. der sieben Städte der Altmark ${ }^{3}$ und der ehemals brandenburgischen Stadt Havelberg das Epitheton ,Hansestadt" als Teil des offiziellen Stadtnamens verwenden zu dürfen, erfolgreich im Fall Lüneburg, das seit September 2007 den Namen „Hansestadt Lüneburg“ trägt. Viele Städte im nordöstlichen Europa, aber nicht nur dort, traten seit Beginn der 1990er Jahre dem 1980 gegründeten „Städtebund Die Hanse“ („Hanse der Neuzeit“) bei, der mit derzeit 163 Mitgliedsstädten aus 15 europäischen Ländern weltweit größten freiwilligen Städtegemeinschaft. ${ }^{4}$ Seit 1992 finden die jährlichen Hansetage dieses Städtebundes auch in Städten außerhalb Deutschlands, der Niederlande und Schwedens statt: 1992 Tallinn, 1996 Bergen, 1997 Gdańsk, 2001 Riga, 2004 Turku und 2005 Tartu.

Im Wortsinne greifbar wurde und wird das neue Interesse an der Hanse mit der Herausgabe einer 10-€-Sondermünze ,650 Jahre Städtehanse“ im Jahr 2006 durch die Bundesrepublik Deutschland zur Würdigung des ersten allgemeinen Hansetags von $1356^{5}$ und der aus demselben Grund veröffentlichten, reich mit Illustrationen und Faksimiles von Quellen ausgestatteten Loseblattsammlung der Deutschen Post zum Thema ,Die Hanse Mythos des Spätmittelalters'.6 Wirtschaftskreise besinnen sich auf die Kraft positiver Tradition, den „Spirit“ der Hanse, und verweisen auf Innovationsgeist, Weltoffenheit und Zukunftsorientierung in freier Selbständigkeit, die gleichermaßen die Hansekaufleute und die jungen Entrepreneurs von heute auszeichneten. So sei z. B. Lübeck ,auf dem besten Wege, die zeitlosen Maßstäbe seiner Geschichte zu revitalisieren und zum Motor zukünftiger Erfolge zu machen". ${ }^{7}$ Auf Initiative der Hamburger

\footnotetext{
${ }^{3}$ Salzwedel, Gardelegen, Tangermünde, Osterburg, Seehausen, Werben und Stendal.

${ }^{4}$ http://www.hanse.org/de. - Jürgen BOHMBACH, Die neue Hanse - Mythos und Realität, in: Antjekathrin GrassmanN (Hg.), Ausklang und Nachklang der Hanse im 19. und 20. Jahrhundert (Hansische Studien XII), Trier 2001, S. 89-100; Thomas HILL, Vom öffentlichen Gebrauch der Hansegeschichte und Hanseforschung im 19. und 20. Jahrhundert, in: ebd., S. 67-88.

${ }^{5} 10-€$-Sondermünze „650 Jahre Städtehanse“. Auszug aus dem Protokoll des Münzwettbewerbs, in: Numismatisches Nachrichtenblatt Heft 1, 2006, S. 16 f.

${ }^{6}$ Deutsche Post, Philatelie, im Rahmen der Dokumentationen großer Jubiläen und besonderer Ausgabeanlässe. Die Loseblattsammlung umfasst sechs Lieferungen, die u. a. je vier Faksimiledrucke, meist archivalischer Quellen, enthalten. Die Auflage ist auf 10.000 Exemplare limitiert. Bei Manuskriptabschluss waren vier der sechs Lieferungen erschienen.

${ }^{7}$ Björn ENGHOLM (Hg.), Zukunft Hanse - Wertorientierungen einer Stadt im Aufbruch.
} 
Handelskammer bildete sich 2005 die ,Gemeinschaft der Hansekaufleute des Stalhofs“ und veranstaltet ihre jährliche Zusammenkunft als „Hamburger Morgensprache“ unter dem Motto „Freiheit des Geistes, der Chancen und des Handels“. Sie soll an die Frühzeit der Hamburger Kaufmannschaft crinnern - ,an die Gründung der Hanse und ihres berühmtesten Kontors in London. Diese Wiederbelebung alter hanseatischer Traditionen [leiste] einen wichtigen Beitrag zum weltweiten Marketing" Hamburgs. Die Mitglieder des Kontorvorstandes (Zwölferrats) sind bei den ,Morgensprachen' in rote Roben und schwarze Barette gewandet, die Zeremonie folgt anscheinend akribisch dem Statutenbuch von $1457^{8}$ - aber eben mit dem Unterschied, daß solche „Morgensprachen“ zwar am Londoner Stalhof, jedoch nie in Hamburg stattfanden. ${ }^{9}$ In einer Firmenzeitschrift läuft derzeit eine mehrteilige Serie über die Hanse. ${ }^{10}$ Das leitet über zu den Medien, die auch nicht abseits stehen: Bereits 1994 titulierte das „National Geographic“-Magazin „The Hanseatic League. Europe's first Common Market"," während die Hanse im vierten Teil der Spiegelserie „Woher kommt Europa?“ 2002 unter dem Titel „Grenzenlose Gewinne“ als „die EU des Mittelalters“ bezeichnet wurde. ${ }^{12}$ Das Motto des „12. Medientreff[s] unter Segel“ vom 2. bis 9. Juni 2007 lautete: „Die Hanse ein Vorläufer der Europäischen Union“. Die Organisatoren argumentierten, ,dass eine friedliche Koexistenz der Staaten durch eine starke wirtschaftliche Klammer im Jahre 1161 begründet“ worden sei, als ,ein Vertrag zwischen Heinrich dem Löwen und den Herrschern über die schwedische Küste den deutschen Kaufleuten einen Zutritt zum gotländischen

Lübecker Exzellenz-Geschichten aus Technologie, Logistik, Wissenschaft und Kultur, Lübeck 2006; die Zitate auf S. 9.

${ }^{8}$ Jörn ARFS, Hamburger Morgensprache. Tradition trifft Moderne, in: hamburger wirtschaft 60, 2005, Heft 7, S. 56-58. Zitate aus der Internetseite der ,Hamburger Morgensprache": http://quickplace.ihk.de/QuickPlace/hh morgensprache/Main.nsf-52k (22.08.2007). Die Veranstaltungen haben ein zwiespältiges Echo in der Presse; s. z. B. Die Welt vom 6.6.2005, Hamburger Abendblatt vom 8.6.2005, S. 12; Hinz \& Kunzt, Nr. 149, Juli 2005 , S. 46; Die Welt vom 19.6.2006, S. 33 und 39; s. auch hamburger wirtschaft 62, 2007, Heft 7, S. $48-49$.

9 ... und die Versammlung nicht nur Hamburger, sondern alle hansischen Kaufleute betraf, die sich im Stalhof aufhielten; außerdem sind die Statuten aus dem Jahr 1437: Sie sind am besten zugänglich veröffentlicht in Rolf SPRANDEL (Hg.), Quellen zur Hanse-Geschichte (Ausgewählte Quellen zur deutschen Geschichte des Mittelalters; Bd. 36), Darmstadt 1982, S. $350 \mathrm{ff}$; s. dazu Nils JÖRN, „With money and bloode«. Der Londoner Stalhof im Spannungsfeld der englisch-hansischen Beziehungen im 15. und 16. Jahrhundert (QDhG, N.F., Bd. 50), Köln u. a. 2000, S. 304-311.

${ }^{10}$ Zeitdruck. Für Kunden und Freunde der Druckerei Hahn GmbH, ab Heft 2, 2007.

${ }^{11}$ National Geographic, Vol. 186, no. 4, S. 56-79, von Edward VON DER PORTEN.

${ }^{12}$ Wolfram BICKERICH, Grenzenlose Gewinne, in: Der Spiegel Nr. 5 vom 28.01.2002, S. 138-148, hier S. 142. 
Handelshof im russischen Novgorod" eröffnet habe. ${ }^{13}$ In Lübeck wird eine „Konzeptstudie und eine Vorplanung“ für ein europäisches Hansemuseum mit Hilfe von Stiftungsmitteln erarbeitet, ${ }^{14}$ Lüneburg will das Thema Hanse bei der Neuordnung der Museumslandschaft nutzen und schließlich zeigt der vorgesehene Ausbau des Hansaparks bei Sierksdorf um einen $40.000 \mathrm{~m}^{2}$ großen Bereich „Hanse“ mit Holstentor, Kaufmannspeicher und Kontoren im Maßstab 1:1,5 ${ }^{15}$ die hohe Akzeptanz des Themas auch auf der Ebene der Freizeitgestaltung im Vergnügungspark. ${ }^{16}$

Worin besteht diese Akzeptanz? Es sind nach wie vor - seit ca. 150 Jahren - die positiv konnotierten Eigenschaften, die der Hanse bzw. den hansischen Kaufleuten zugeschrieben werden: Verlässlichkeit, Vertrauenswürdigkeit und kaufmännische Ehrlichkeit, heutzutage aber ergänzt durch Innovationsgeist und Weltoffenheit, respektive weltoffenes Bürgertum und tatkräftigen Bürgersinn. ${ }^{17}$ In den städtischen Verwaltungen besinnt man sich auf dieser Grundlage aus Marketinggründen auf die hansische Vergangenheit, denn mit dem Titel „Hansestadt“ lässt sich eine Kommune im Kampf um Anteile am Tourismusmarkt besser ,positionieren“. Die Hanse hat in (Teilen) der Öffentlichkeit folglich eine Prestigefunktion. Wenn diese Prestigefunktion inhaltlich untermauert werden soll, richtet sich das neu erwachte Interesse meist auf Aspekte der Hanse und der hansischen Geschichte, die Parallelen zur Gegenwart haben oder zu haben scheinen. Am

\footnotetext{
${ }^{13} \mathrm{http} / / \mathrm{www} . \mathrm{medientreff-unter-segel.de/event2007/hintergrund.php.} \mathrm{-} \mathrm{Der} \mathrm{positiven} \mathrm{Aus-}$ sage in der Überschrift wird in den „Hintergrundinformationen zum Thema der Regatta“ immerhin ein Fragezeichen beigesellt: „Die Hanse - Ein Vorläufer der Europäischen Union?“ - Unter der o. g. Internetadresse stehen als „Hintergrundinformationen zum Thema der Regatta: Was sagt ein Hanse-Historiker zum Motto" die S. 28f., 32-41 des folgenden Beitrags, leicht überarbeitet und ohne Nachweise.

${ }_{14}^{14}$ Bislang letzter Bericht in den Lübecker Nachrichten vom 13.03.2007.

${ }^{15}$ Lüneburg: Pressedienst der Stadt Lüneburg. http://www.lueneburg.de (10.09.2007); Hansapark: http://www.hansapark.de/freizeitpark/medien-und-presse-pressebilder_DE.php (27.08.2007).

${ }^{16}$ Die hier vorgestellte Auswahl ist bei weitem nicht vollständig; sie kann z. B. erweitert werden durch die Suche nach dem Stichwort „Hanse“ in einer der gängigen Internet-Suchmaschinen; s. dazu in Kürze Alexander KREY, Yorrick WIRTH, Die Hanse im Internet, in: Rolf Hammel-Kiesow, Rudolf HolbaCH (Hg.), Die Hanse in den Medien und in der Öffentlichkeit (Hansische Studien, vermutlich Bd. 18), Trier in Vorbereitung für 2008.

${ }^{17}$ Die Werbekraft des Epithetons Hanse und der damit verbundenen Eigenschaften - neben den o. g. vor allem Solidität und Solidarität - besteht durchgehend seit der zweiten Hälfte des 19. Jh.s (durch sämtliche ideologischen Einvernahmen hindurch; dazu Rolf HAMMEL-KIESow, Die Hanse, 3. aktualisierte Auflage München 2004, S. 7f.) wenn auch mit unterschiedlichen ,Konjunkturen“; s. Rainer POSTEL, Treuhänder und Erben: Das Nachleben der Hanse, in: Jörgen Bracker ( $\mathrm{Hg}$.): Die Hanse - Lebenswirklichkeit und Mythos, Bd. 1, Hamburg 1989, S. 667-679, hier S. 677-679. - Im zweiten Band der von Etienne FraNCOIS und Hagen SCHULZE hg. Deutsche[n] Erinnerungsorte[n]. München 2001, ist der Beitrag von Dirk SCHÜMER, Die Hanse, S. 369-386, dem Abschnitt „Leistung“ zugeordnet.
} 
häufigsten herangezogen werden die Begriffe ,Ostseeraum“ oder ,Ostseeregion“, ,Europäische Union“ und ,Globalisierung'.

Wie geht man nun als Historiker mit diesem Interesse um, das in den meisten Fällen ja nicht durch historisch-kritische Interpretation der Überlieferung, geläutert 'ist? Wie bei allen Arten der Einvernahme historischer Phänomene in jeweils gegenwärtige Bezüge ziehen sich manche Historiker in eine ,Ohne-mich-Haltung ' zurück, um durch ihre Äußerungen nicht Missverständnissen und Missinterpretationen Vorschub zu leisten. Aufgabe der Geschichtswissenschaft ist es jedoch, das Interesse der Öffentlichkeit aufzugreifen und anhand ihres Fachwissens und ihrer spezifischen historischen Methode die Möglichkeiten und Grenzen dieser ,Einvernahmen' in gegenwärtige Bezüge aufzuzeigen. Die Gefahr missverstanden zu werden, besteht immer, darf aber nicht davon abhalten, sich Fragen oder auch Behauptungen zu stellen, die in der Öffentlichkeit verbreitet sind und verbreitet werden. ${ }^{18}$

Schließlich beschäftigen sich auch Vertreter der historischen Wissenschaften mit Aspekten dieser Fragen, ${ }^{19}$ aber eben mit Fragestellungen der historischen Disziplinen, auf Grund derer Parallelen zur Jetztzeit, wenn überhaupt, weniger plakativ gezogen werden. Außerdem sind die Veröffentlichungen der Ergebnisse für die interessierten Laien oft zu detailliert und zu wenig allgemein verständlich. Teil dieser fachimmanenten europäischen Perspektive auf die Geschichte der Ostseeregion ist auch die Konzeption des Heftes 2-3 der polnischen Zeitschrift Zapiski Historyczne 71, 2006, das, unter dem Titel „Mare Balticum - mare clausum oder mare liberum?", verschiedene Aspekte der gemeinsamen Geschichte der Ostseeanrainerstaaten präsentiert ${ }^{20}$ und den Anlass für die erste

\footnotetext{
${ }^{18}$ Siehe dazu Klaus BergmanN, Gegenwarts- und Zukunftsbezogenheit, in: Ders. u. a. (Hg.), Handbuch der Geschichtsdidaktik, 5. überarb. Aufl. Seelze-Velber 1997, S. 266-268.

${ }_{19}$ Als ein Beispiel sei das internationale Forschungsprojekt „Culture Clash or Compromise. The importance of regional strategies in the Europeanization of the Baltic Rim 1100-1400

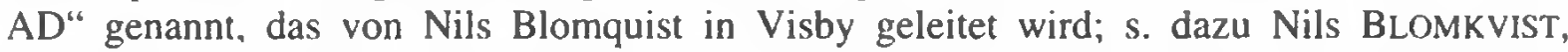
Sven-Olof LINDQVIST (Hg.), Europeans or Not? Local Level Strategies on the Baltic Rim 1100-1400 AD. Kalmar Conference 1998, (CCC-papers 1), Visby - Kalmar 1999; zuletzt Detlef KatTinger, Jens E. Olesen, Horst Wernicke (Hg.), Der Ostseeraum und Kontinentaleuropa 1100-1600. Einflussnahme - Rezeption - Wandel (Culture Clash or Compromise; 8), Schwerin 2004.

${ }^{20}$ Henryk SAMSONOWICZ, Strefa bałtycka: jednoćs czy zrónicowanie? [Der Ostseeraum: Einheit oder Differenzierung?], in: Zapiski Historyczne 71, Heft 2-3, 2006, S. 25-38: Rolf Hammel-Kiesow, Hanza i Europa [Die Hanse und Europa], S. 39-68; Michael NorTh, „Niderlandyzacja“" strefy Morza Bałtyckiego [Die Niederlandisierung des Ostseeraums], S. 69-80; Ralph TUCHTENHAGEN, Szwedzkie dominium maris Baltici w epoce wczesnonowocytnej [Das schwedische dominium maris Baltici in der frühen Neuzeit], S. 81-106; Edward WŁODARCZYK, Europejskie uwarunkowania i powiązania rozwoju gospodarczego portów południowego Bałtyku w XIX wieku (1815-1914) [Europäische Voraussetzungen und
} 
Fassung des folgenden, nochmals überarbeiteten und erweiterten Beitrags gab.

Die Frage nach dem Verhältnis von „Hanse und Europa“ ist nicht neu was angesichts des geographischen Rahmens des hansischen Handels und der hansischen Politik einerseits zwar nicht erstaunt, andererseits aufgrund der jeweils nationalen Ausrichtung der Geschichtswissenschaft in den europäischen Staaten aber auch nicht oft vorkam. 1921 widmete Fritz Rörig ihr einen Beitrag u. d. T. „Die Hanse, ihre europäische und nationale Bedeutung", in dem viel von der nationalen, aber nur eine knappe Seite von der europäischen Bedeutung die Rede ist. ${ }^{21}$ Rund 60 Jahre später umriss Heinz Stoob die Geschichte der Hanse als die eines „Gefüge[s]“ mit „quasi unverfasster Ordnung" in Europa, ausgehend von dem Reichsfreiheitsprivileg für Lübeck 1226 und dem Smolensker Vertrag 1229 bis zum Niedergang der Hanse ab etwa 1570, den er aus der einseitigen Orientierung auf den Ostseeraum gelöst und in weitere europäische Zusammenhänge wie z. B. eine allgemeine Erschöpfung des Bürgertums in Frankreich, Spanien, Italien und Ungarn gestellt sehen wollte. ${ }^{22}$ Während Stoob seinem Titel „Hanse u n d Europa“ entsprechend mehr das Wirken der Hanse in Europa zum Thema hatte, betonte Heinrich Sproemberg bereits 1959/1961 in dem fundiertesten ,Europa-Beitrag ' die europäischen $\mathrm{Zu}$ sammenhänge der Entwicklungen z. B. im Städtewesen, im Kredit- und Geldwesen sowie den Siedlungsbewegungen und bezeichnete als Mission der Hanse, ,dass sie den Norden und Osten stärker und dauernder an den Okzident angeschlossen hat" und dass man den europäischen Charakter der Hanse erst richtig würdige, „wenn man nicht nur den Gesichtspunkt aufstellt, was der deutsche Kaufmann geleistet hat, sondern wenn man das Geben und Nehmen zwischen der Hanse und ihren verschiedenen Handelspartnern als das entscheidende Moment für die Wirkung ihrer Tätigkeit betrachtet"“. ${ }^{23}$ Einen Rückschritt stellte demgegenüber die erste große

Verflechtungen beim wirtschaftlichen Aufschwung der Häfen an der südlichen Ostsee im 19. Jahrhundert (1815-1914)], S. 107-124.

${ }^{21}$ Fritz RöRIG, Die Hanse, ihre europäische und nationale Bedeutung, in: Deutsche Rundschau 188, 1921, S. 265-277, hier 272f.; Rörig sieht die europäische Bedeutung in der Verbindung der beiden bis dahin getrennten Nord-Süd-Verbindungen England-Rheintal-Italien und Finnischer Meerbusen-Schwarzes Meer durch die Brücke Brügge-Lübeck-Novgorod, ,die Nordeuropa immer mehr zu einer zwar differenzierten. aber dennoch geschlossenen großen Wirtschaftsgemeinschaft zusammenwachsen lie $B^{*}$ (ebd.). - Zu Rörig s. nun die sehr gute kritische Aufarbeitung seiner wissenschaftlichen Leistung durch Birgit NoODT, Fritz RÖRIG, Lübeck, Hanse und Volksgeschichte, in: ZVLGA 87, 2007.

${ }^{22}$ Heinz Stoob, Die Hanse und Europa bis zum Aufgang der Neuzeit, in: H. Dollinger, H. GRÜNDER, A. HAUSCHMIDT (Hg.): Weltpolitik. Europagedanke, Regionalismus. Fs. für Heinz Gollwitzer zum 65. Geburtstag, Münster 1982, S. 1-17; Zitate S. 7, Niedergang S. 13.

${ }^{23}$ Heinrich Sproemberg, Die Hanse in europäischer Sicht, in: Annales de la Société 
Hanseausstellung in Köln 1973 dar, die unter dem Titel „Hanse in Europa. Brücke zwischen den Märkten. 12. bis 17. Jahrhundert" trotz eines überzeugenden Aufgebots an internationalen Autoren die Hanse nur als Organisation in Europa betrachtete, ohne auf den von Sproemberg gewiesenen Weg auch nur hinzuweisen. ${ }^{24}$

Wenn wir uns, veranlasst durch das öffentliche Interesse an ,Hanse und Europa', wieder diesem Thema zuwenden, muss als erstes - die Selbstverständlichkeit - klargestellt werden, dass ,Europäische Union“ und ,Globalisierung ' in dem halben Jahrtausend zwischen der Mitte des 12. Jahrhunderts, als die frühhansische Zeit begann, und dem Ende des 17. Jahrhunderts, als die Hanse sich auflöste, ${ }^{25}$ keine zeitgenössischen Begriffe waren. Der Begriff ,Europa“ war zwar bekannt, auf ihn werden wir im Folgenden etwas näher eingehen, aber die Bewohner Europas im Spätmittelalter und in der frühen Neuzeit hätten sich allenfalls unter ,Ostseeregion' etwas vorstellen können. Dennoch ist das Verfahren, Leitbegriffe der Gegenwart auf die Vergangenheit anzuwenden, legitim, denn wir schreiben die Geschichte jeweils aus unserer Lebenswirklichkeit heraus, gegenwärtig folglich aus derjenigen des frühen 21. Jahrhunderts. Deren große politische, gesellschaftliche und wirtschaftliche Themen in unserem Erdteil sind das Europa, das seit dem 18. Jahrhundert als Idee entstand, und die Globalisierung, in die dieses Europa in den Augen vieler mehr erleidend als handelnd eingebunden ist. Folglich müssen wir auch fragen, auf welchen Grundlagen diese Idee von Europa entstand ${ }^{26}$ und in

Royale d'Archéologie de Bruxelles, Bd. 50, 1961, S. 221-224 (zitiert nach einem Sonderdruck mit Paginierung 1-14), Zitate S. 13.; DERS.. Die Hanse in europäischer Sicht, in: Dancwerc. Opstellen angeboden aan Prof. Dr. D. Th. Enklaar, Groningen 1959, S. 127-151.

${ }^{24}$ Kölnisches Stadtmuseum (Hg.), Hanse in Europa. Brücke zwischen den Märkten 12.-17. Jahrhundert (Katalog zur Ausstellung), Köln 1973

${ }^{25}$ Zur Geschichte der Hanse Philippe Dollinger, Die Hanse, 5. erweiterte Auflage Stuttgart 1998; HaMmEL-KIESOW, Hanse (wie Anm. 17).

${ }^{26}$ Zur Entstehung der Idee Europa s. Jacques LE GoFF, Das alte Europa und die Welt der Moderne, München 1996; DERS.: Die Geburt Europas im Mittelalter, München ${ }^{2} 2004$ (französische Originalausgabe Paris 2003); Wolfgang SCHMALE, Geschichte Europas. Wien u. a. 2000; Ferdinand SEIBT, Die Begründung Europas. Ein Zwischenbericht über die letzten tausend Jahre. Frankfurt/Main 2002; Rudolf SCHIEFER, Einheit in Vielfalt. in: Frankfurter Allgemeine Zeitung Nr. 284 vom 06.12.2005, S. 7; Hans JOAS, Klaus WIEGANDT (Hg.), Die kulturellen Werte Europas, Frankfurt am Main 2005. - Speziell zu den Vorstellungen von Europa im Mittelalter s. Klaus OSCHEMA. Europa in der mediävistischen Forschung - eine Skizze. In: Rainer C. SCHWinges; Christian HeSSE; Peter MORAW, (Hg.), Europa im späten Mittelalter. Politik - Gesellschaft - Kultur (HZ, Beiheft 40). München 2005, S. 11-32; DERS., Der Europa-Begriff im Hoch- und Spätmittelalter. Zwischen geographischem Weltbild und kultureller Konnotation, in: Jahrbuch für Europäische Geschichte 2, 2001, S. 191-235; Bernd SCHNEIDMÜLLER, Die mittelalterlichen Konstruktionen Europas. Konvergenz und Differenzierung, in: Heinz DuchHARD; Andreas KUNZ, (Hg.): „Europäische Geschichte“ als historiographisches Problem. Mainz 1997, S. 5-24; Basileios KARAGEORGOS, Der Begriff Europa im Hoch- und Spätmittelalter, in: DA 48, 1992, S. 137-164. 
aller gebotenen Kürze zeigen, dass der Prozess der ,Globalisierung ' verstanden als Aufbau, Verdichtung und zunehmende Bedeutung weltbzw. im Falle der Hanse europaweiter Vernetzung - das Europa des Mittelalters und der frühen Neuzeit prägte, bislang aber kaum zur Kenntnis genommen wurde, weil das bisherige Deutungsrepertoire der Geschichtswissenschaft die Zusammenhänge zwischen Völkern, Staaten und Zivilisationen (fast) nur im nationalen und regionalen Rahmen sah. ${ }^{27}$ In diesem Zusammenhang werden wir uns dem Thema Hanse in zwei Ansätzen nähern, einem historischen und einem reflexiven. Historisch ist $\mathrm{zu}$ fragen, inwieweit die Hanse Kontakte zwischen europäischen Regionen intensivierte, die Kenntnis voneinander vermehrte. Der reflexive Ansatz verfolgt die Frage, was die Hanse in unseren heutigen Augen 'modern' macht, wo die strukturellen Ähnlichkeiten der Hanse mit heutigen Phänomenen oder Institutionen liegen, hier folglich mit der Globalisierung und der Europäischen Union.

Zunächst in aller Kürze zu dem Begriff, der der Europäischen Union zugrunde liegt, zu ,Europa': Er soll im Hoch- und Spätmittelalter sowohl im hansischen Raum als auch in anderen Regionen des europäischen Kontinents fast verschwunden gewesen sein. Während im 8. und 9. Jahrhundert das karolingische Reich zu einem fränkischen Europa stilisiert wurde - bereits über die Schlacht bei Poitiers (732) schrieb ein anonymer Chronist, dass den Arabern dort die Europäer gegenüber gestanden hätten (... prospiciunt Europenses Arabum tentoria ordinata / Die Europäer beobachteten die aufgereihten Zelte der Araber) ${ }^{28}$ - soll sich mit dem Zerfall des fränkischen Großreiches Europa als Sache und Begriff aufgelöst haben. ${ }^{29}$ Erst im 15. Jahrhundert hätten Nikolaus von Kues und der Sienenser Aeneas Silvius Piccolomini (später Papst Pius II.) in seinem 1458 verfassten Werk De Europa dem Europa-Begriff seine für viele bis heute gültigen Kontur gegeben: „Die Idee der gemeinsamen kulturellen, christlich begründeten Herkunft über die politische Vielfalt von Völkern und Reichen

${ }^{27}$ Jürgen OSTERhammel, Niels P. PETERSSON, Geschichte der Globalisierung. Dimensionen, Prozesse, Epochen. München 2003, S. 9. 24.

${ }^{28}$ Continuatio Hispana von 754 zu Isidors Historia. in: Monumenta Germaniae Historica. Auctores Antquissimi, Bd. 11, hg. von Theodor MOMMSEN, Berlin 1894, S. 362.

${ }^{29}$ SCHNEIDMÜlleR, Konstruktionen Europas (wie Anm. 26), S. 9-11: KARAGEORGOS, Begriff Europa (wie Anm. 26), S. 137. Nicht als Vorspiel Europas, sondern als Fehlstart definiert demgegenüber LE GoFF, Geburt Europas (wie Anm. 26), S. 52f., im Anschluss an Robert S. LOPEZ, Naissance de L'Europe, Paris 1962, das Karolingerreich, weil in unserer Sicht nicht Einheitsreligion und universeller Staat, sondern ein Komplex politischer Institutionen, weltlichen Wissens u.v.a.m., die ein Mosaik freier Meinungen und unabhängiger Völker untermauerten, Europa definierten. Zum Konstruktionscharakter ,Europas“ s. Anm. 35 . 
hinweg““ ${ }^{30}$ Der Begriff europeus für ,europäisch“, ,Europäer' im Lateinischen sei nun wieder öfter verwendet worden.

In dem langen Zeitraum, der dazwischen lag, sei der Begriff selten gebraucht worden, und wenn, dann meist als geographische Bezeichnung (mit stark wechselndem Rahmen). ${ }^{31}$ Allerdings lässt sich von der Kreuzpredigt Papst Urbans II. (1095), über den Kölner Kanoniker Alexander von Roes (1280er Jahre) bis hin zu Dante Alighieri der politisch und kulturell erweiterte Inhalt vereinzelt greifen, der sich dann seit Nikolaus von Kues und Aeneas Silvius Piccolomini durchsetzen sollte. ${ }^{32}$ Berücksichtigt man dies, so könnte das auffällige Fehlen des Europabegriffs zwischen dem 9. und 15. Jahrhundert auch auf mangelndes Forschungsinteresse zurückzuführen sein. ${ }^{33}$ Festhalten können wir jedoch, dass sich weder hansische Kaufleute noch die Diplomaten der Hanse mit einem Europabegriff auseinander setzten, dass aber das, was sie taten, und was wir als die Geschichte der Hanse kennen, den bis in die 1980er Jahre weit verbreiteten Ansatz, die osteuropäischen Staaten in der Diskussion um das mittelalterliche Europa nicht zu berücksichtigen, ${ }^{34}$ von vornherein desavouiert. Deutlich wird dadurch auch, dass ,Europa ' eine Konstruktion ist, dessen jeweilige Aspekte von den damit befassten Politikern und Wissenschaftlern zusammengestellt werden. ${ }^{35}$ Kommen wir nun aber zu der Frage, was die Hanse in den Augen vieler unserer Zeitgenossen zu einer europäischen Organisation macht.

II. Geographische Grundlagen der Hansegeschichte oder: zum Verhältnis von Raum und ,Staat ' im Wandel der Zeiten

Beim Blick auf eine Europakarte des frühen 21. Jahrhunderts scheint der europäische Charakter der Hanse evident zu sein. Ehemalige Hansestädte (insgesamt rund 200) liegen in acht europäischen Staaten (Deutschland, Niederlande, Belgien ${ }^{36}$, Polen, Russland, Lettland, Estland, Schweden), ehemalige Handelsniederlassungen, sowohl die vier bedeutenden Kontore als auch die mehr als 30 kleineren in weiteren acht (England/Schottland,

\footnotetext{
${ }^{30}$ SCHNEIDMÜller, Konstruktionen Europas (wie Anm. 26), S. 14; OsChEMA, EuropaBegriff (wie Anm. 26), S. 223-226.

${ }^{31}$ LE Goff, Das alte Europa (wie Anm. 26), S. 20, 70f.; DERS.: Geburt Europas (wie Anm. 26), S. 13.

${ }^{32}$ KARAgeorgos, Begriff Europa (wie Anm. 26), S. 139-146; OsChEMA, Europa in der mediävistischen Forschung (wie Anm. 26), S. I6f.; DERS., Europa-Begriff (wie Anm. 26), S. $196 \mathrm{ff}$.

${ }^{33}$ SCHNEIDMÜller, Konstruktionen Europas (wie Anm. 26), S. $11 \mathrm{f}$.

${ }^{34}$ OsCHEMA, Europa in der mediävistischen Forschung (wie Anm. 26), S. 22-26.

${ }^{35}$ Ebd.. S. 30f.; SCHNEIDMÜLlER, Konstruktionen Europas (wie Anm. 26), S. 6-16.

${ }^{36}$ Siehe dazu u. Anm. 39 zu Dinant.
} 
Norwegen, Portugal, Weißrussland, Finnland, Litauen, Dänemark, Frankreich). ${ }^{37}$ Außerdem bestanden Handelsbeziehungen der Hansekaufleute zu weiteren neun (heutigen) europäischen Staaten (Tschechien, Slowakei, Ungarn, Österreich, Schweiz, Luxemburg, Island, Spanien, Italien), so dass insgesamt 25 der heute 45 europäischen Staaten von den "Tätigkeiten“ hansischer Kaufleute erfasst waren - wenn auch in sehr unterschiedlichem Ausmaß. ${ }^{38}$

Die Hansestädte selbst lagen zwischen Zaltbommel an der Mündung des Rheins (Niederlande) im Westen und Dorpat (Tartu/Estland) im Osten und zwischen Stockholm (nur im 14. Jh.) bzw. Visby auf Gotland im Norden und der Linie Köln - Breslau (Wroclaw) - Krakau (Kraków) im Süden, die überwiegende Zahl davon zwischen Rhein und Elbe.

Vorstellungen von der Internationalität der ehemaligen Hanse beruhen im Hinblick auf die ihr angehörenden Städte also darauf, dass die staatliche und ethnische Gliederung des heutigen Europas auf die Zustände des späten Mittelalters projiziert werden und somit belgische (Dinant), niederländische (z. B. Kampen, Zwolle), deutsche, schwedische (Visby, Stockholm), polnische (z. B. Danzig/Gdańsk, Elbing/Elbląg), russische (Königsberg/Kaliningrad), lettische (Riga) und estnische (Reval/Tallinn, Dorpat/Tartu) Städte als Mitglieder der Hanse betrachtet werden.

Projiziert man die Hansestädte jedoch auf eine Landkarte des spätmittelalterlichen Europas um 1400, verändert sich das Bild grundlegend. Fast alle Hansestädte lagen damals auf dem Gebiet des Heiligen Römischen Reiches und in dem Territorium des Deutschen Ordens, das zwar nicht zum Reich gehörte, aber ein von deutschem Adel und deutschen Städten, zu weiten Teilen auch von deutschen Bauern geprägtes Herrschaftsgebiet war. Die einzigen Städte, die nicht in diesen beiden Gebieten lagen, waren im Osten die Hansestadt Krakau in Polen sowie im Norden die Hansestädte Visby auf Gotland und im 14. Jahrhundert Stockholm in Schweden, im Westen wird häufig Dinant an der Maas im heutigen Belgien dazu gezählt. ${ }^{39}$ Einige holländische und seeländische Städte wie Amsterdam

${ }^{37}$ Wobei in weiteren drei der Staaten, in denen ehemalige Hansestädte lagen, sich auch Handelsniederlassungen befanden: Betgien: Antwerpen, Brügge (zu Dinant s. Anm. 39); Russland: Novgorod, Pskov und Smolensk (Hansestadt Königsberg, heute Kaliningrad); Schweden: Kalmar, Åhus, Ystad usw., Hansestadt waren Visby und im 14. Jh. Stockholm. In Weißrussland (Belarus) lagen die Handelsniederlassungen in Polozk und Vitebsk.

${ }^{38}$ Wie viel ,Europa' die Hanse flächenmäßig erfasste wird deutlicher, wenn man berücksichtigt, dass fünf der 45 Staaten Kleinstaaten sind (Andorra, Liechtenstein, Monaco, San Marino, Vatikan).

${ }^{39}$ Dinant war streng genommen keine Hansestadt. Dinanter Kaufleute genossen in England die hansischen Privilegien, sie gehörten zum Recht des Kaufmanns zu London. Die Gesandten des Londoner Kontors sagten auf dem Hamburger Hansetag 1465, dass die Stadt „nicht in der Hanse“ sei, dass aber die Dinanter Kaufleute mede in de besittinge der privilegien 
und Zieriksee, die seit den 50er Jahren des 14. Jahrhunderts eine eigene Fitte (Niederlassung) auf Schonen besaßen ${ }^{40}$ und in den $1370 \mathrm{er}$ und 1380er Jahren offiziell und gleichberechtigt hansische Tagfahrten (Hansetage) besuchten, ebenso wie auch die holländische Stadt Dordrecht, ${ }^{41}$ gehörten wie die ostniederländischen Städte - z. B. Kampen, Zutphen, Zwolle - bis 1648 zum Reich.

Dieser Befund vermittelt indirekt das wesentliche Zugehörigkeitskriterium zur Hanse: Zugelassen waren nur niederdeutsche Kaufleute sowie Städte, in denen niederdeutsche Kaufleute eine führende Position im Rat innehatten. ${ }^{42}$ Dieses Kriterium traf sowohl für die niederdeutschen Städte innerhalb der Reichsgrenzen zu wie auch für die außerhalb der Reichsgrenzen liegenden Städte in Preußen und Livland, der damaligen Bezeichnung für Estland und Lettland, wo deutsche Kaufleute und Handwerker die Stadtbürger und vor allem deren Führungsgruppen stellten, die einheimischen Prussen, Esten und Liven dagegen die unterbürgerlichen Schichten und die Landbevölkerung. Dieses Kriterium traf auch zu für Krakau, in weiten Teilen für Visby und Stockholm (im 14. Jahrhundert) und die Bürger der niederländischen Städte wurden bis in das 17. Jahrhundert hinein als Teil der großen mittelniederdeutschen Sprachfamilie angesehen. In dieser Sprache erfolgte die Kommunikation - zumindest der Kaufleute - in diesem riesigen Gebiet. Bis in die frühe Neuzeit hinein sorgten die unterschiedlichen Formen des Mittelniederdeutschen und ihre Anwendung in den Handelsniederlassungen dafür, dass selbst die weit entfernten Außenposten dieser Region sprachlich näher zueinander standen als man früher dachte. Geschriebene Texte konnten ohne große Schwierigkeiten überall in diesem Gebiet verstanden werden. Die münd-

gedegedinget seien; HR II, 5, Nr. 712, $\$ 45$, S. 500. Dinant hat, soweit wir wissen, keine Versuche unternommen, an anderen hansischen Rechten außer in England beteiligt zu werden. Die Stadt selbst ist von den Hansestädten zu Tagfahrten nicht eingeladen worden und erscheint auch nicht in den Listen und Zusammenstellungen der Hansestädte; Walther STEIN, Die Hansestädte, II. Die einzelnen Hansestädte, in: HGbll. Bd. 19, Jg. 1913, S. 519-560, hier 559f.; ausführlich J. M. LAPPENBERG, Urkundliche Geschichte des hansischen Stahlhofes zu London, Hamburg 1851, Erste Abtheilung, S. 35f.

${ }^{40}$ Dieter SEIFERT, Kompagnons und Konkurrenten. Holland und die Hanse im späten Mittelalter (QDhG; N.F., Bd. 43), Köln u. a. 1997, S. 38-40; dazu Hansisches Urkundenbuch (im folgenden: HUB) 3, 553 [Amsterdam] u. 4, 79 [Zieriksee].

${ }^{41}$ SEIFERT, Kompagnons (wie Anm. 40), S. 92-113: Zieriksee 1374, Hanserezesse. Die Rezesse und andere Akten der Hansetage 1256-1430 (im Folgenden: HR) I. Abt., 2, bearb. von Karl KoppManN, Leipzig 1872, Nr. 77, S. 86-89; 1375, ebd. Nr. 86, S. 98-102. Amsterdamer Ratsendeboten waren Mitglieder der Gesandtschaft, die 1376 einen endgültigen Frieden mit Norwegen aushandelten (HR I, 2, Nr. 123, 125, S. 135ff.). Zu Dordrecht SEIFERT, Kompagnons, S. 112.

${ }^{42}$ Zuletzt Ernst PITZ, Bürgereinung und Städteeinung. Studien zur Verfassungsgeschichte der Hansestädte und der deutschen Hanse (QDhG, N.F., Bd. 52), Köln u. a. 2001, S. 295 f. 
liche Kommunikation war wegen der unterschiedlichen Dialekte schwieriger, aber linguistisch betrachtet waren die Niederlande ein integraler Teil des mittelniederdeutschen Sprachgebiets, in dem die Einwohner der Niederlande ihre eigene Sprache nutzen konnten, um ihre Geschäfte in den Gebieten rund um die Ostsee abzuschließen. ${ }^{43}$

Man kann folglich nicht behaupten, die Hanse sei eine ,europäische“ Organisation gewesen. ${ }^{44}$ Sie war allerdings europaweit tätig: Die Hanse vertrat die wirtschaftlichen Interessen der niederdeutschen Kaufleute im Zwischenhandel auf der Hauptachse von Russland nach Flandern und England sowie in Skandinavien, einem Gebiet, das Ende des 13. Jahrhunderts rund $500.000 \mathrm{~km}^{2}$ umfasste. Seit dem späten 14. Jahrhundert wurde der Handel zur französischen Westküste, nach Spanien, Portugal, Italien und nach Island ausgedehnt, so dass der Handelsraum ca. 6 Millionen qkm maß. Nur im nördlichen Europa (Ausnahme: Spanien 1607) - und fast ausschließlich in Städten, die mit Schiffen zu erreichen waren - erwarb die Hanse Handelsprivilegien für ihre Mitglieder. Der Handel ins Binnenland des Reiches und weiter nach Süden war Individualhandel der Kaufleute ohne institutionelle Unterstützung durch die Hanse. Hauptstützpunkte des hansischen Handels waren die Kontore (Niederlassungen) in Novgorod (Russland), Bergen (Norwegen), London (England), Brügge (Flandern/Belgien), seit dem 16. Jahrhundert Antwerpen (Belgien), sowie mehr als 30 Faktoreien (kleinere Niederlassungen) von Litauen bis Portugal.

An der Frage, ob diese europaweiten Aktivitäten und Verbindungen der hansischen Kaufleute Segen oder Fluch für die betroffenen Regionen und Länder waren, schieden sich bis in die 60er Jahre des 20. Jahrhunderts die Geister (der Historiker), wobei die Bewertungskriterien fast durchweg aus der jeweiligen Gegenwart genommen wurden und die Hanse und ihre Partner oder Konkurrenten nur die Folie für die Streitigkeiten zwischen den (einzelnen Vertretern der) Nationen des späten 19. und der ersten Hälfte des 20. Jahrhunderts abgaben. Aufgrund der aggressiven Politik des kaiserlichen und des nationalsozialistischen Deutschlands in diesem Zeitraum nimmt es nicht Wunder, dass die Hanse von nichtdeutschen Historikern eher kritisch bis feindselig beurteilt wurde. Besonders die hansische Präsenz in Norwegen geriet so im Nachhinein zur Ausbeutung eines ganzen Volkes. ${ }^{45}$

\footnotetext{
${ }^{43}$ Janis KRESLINS, Linguistic Landscapes in the Baltic, in: Scandinavian Journal of History 28, 2003, S. 165-174, hier 168-170.

${ }^{44}$ Albert D'Haenens. Die Welt der Hanse. Antwerpen 1984, S. 419, sieht die ,ursprüngliche Kohärenz", die „Anfangskohärenz" in Bezug auf die Vollendung europäischer Pläne in der Geschichte der Hanse; sie gälte es wieder herzustellen!

${ }^{45}$ Siehe dazu unten Anm. 76.
} 
In der Zwischenzeit haben die Historiker gelernt, in wie starkem Maße ihre Erkenntnisse von ihrer jeweiligen Lebenswelt bestimmt sind. ${ }^{46}$ Vor allem die hansische Geschichtsforschung hat davon profitiert, dass die großen wirtschaftlichen und politischen Umwälzungen des späten 20. Jahrhunderts ihr Modelle zwischenstaatlichcr Bczichungen und wirtschaftlicher Organisationsformen an die Hand gaben, die in der Hochzeit des Nationalstaats mit den nationalen Volkswirtschaften nicht denkbar oder besser: nicht mehrheitsfähig waren oder gewesen wären. ${ }^{47}$ Der gegenwärtigen Geschichtsforschung verhelfen sie aber dazu, die komplizierten Beziehungen der Hansestädte untereinander, zu ihren Stadt- und Landesherren, zu Kaiser und Reich sowie die Organisation des hansischen Handels besser zu verstehen.

Fragen wir nun also aus unserer heutigen Lebenswelt heraus nach den europäischen Komponenten der Hanse.

\section{Der historische Ansatz: Europaweite Beziehungen der Hanse} in Handel und Diplomatie

Die europäische Funktion des hansischen Handels dürfte unumstritten sein. Der Titel der ersten großen Hanseausstellung, die 1973 in Köln stattfand: ,Die Hanse - Brücke zwischen den Märkten“ brachte diesen Aspekt auf den Punkt. Dieser Brückenschlag war freilich keine originäre Leistung der Hansekaufleute, denn viele Handelsverbindungen bestanden bereits, bevor die frühhansischen Kaufleute sich anschickten, sich an diesem Handel zu beteiligen und zwar schließlich so erfolgreich, dass sie die meisten Konkurrenten für einen je nach Handelsrichtung unterschiedlichen Zeitraum verdrängen konnten. Ihre Leistung bestand darin, dass sie die Intensität und die Dichte der Beziehungen gegenüber der vorhansischen Zeit vervielfachten. Ein Monopol konnten die Hansekaufleute jedoch nirgendwo durchsetzen. Allerdings gab es unterschiedliche Annäherungswerte; in Bergen war man im Stockfischhandel relativ nah am Monopol, ebenso z. B. in Schweden in den zwei Jahren unmittelbar nach dem Privileg von Strängnas (1523) bis Gustav Vasa dann bereits 1525 den Niederländern erste Verkehrsmöglichkeiten einräumte. ${ }^{48}$ In der Regel aber bestand in

\footnotetext{
${ }^{46}$ Der auf Edmund Husserl zurückgehende Begriff der ,Lebenswelt " hat sich in den 50er und 60er Jahren des 20. Jh.s für den vorwissenschaftlichen Entscheidungsbereich des Historikers, für die Beeinflussungsstrukturen, eingebürgert; s. dazu Theodor SCHIEDER, Einleitung, in: DERS., Kurt GRÄUBIG (Hg.). Theorieprobleme der Geschichtswissenschaft (Wege der Forschung, Bd. 378), Darmstadt 1977, S. VII-XXXV, hier S. XVIIff.

${ }^{47}$ Hammel-KIESOW, Hanse (wie Anm. 17), S. $13 \mathrm{ff}$; ; siehe dazu auch unten, Teil IV, S. $28 \mathrm{ff}$.

${ }^{48}$ Allerdings betraf das vor allem Lübeck und wenige andere Hansestädte, deren Zahl von
} 
sämtlichen Zielländern der Hanse der Eigenhandel der einheimischen Kaufleute weiter fort, wenn auch auf unterschiedlichem Niveau. ${ }^{49}$

Der große Wettbewerbsvorteil der hansischen Kaufleute lag in der groBen Nachfrage in den mittel- und westeuropäischen Absatzgebieten. Denn die Hansekaufleute waren in einer Zeit enormer Bevölkerungszunahme und kräftigen Wirtschaftswachstums angetreten und verstanden es, aufgrund der großen Mengen an Handelsgütern, die sie in den Zielländern ihres Handels kauften und dafür Silber und andere Handelswaren lieferten, sich den dortigen Machthabern unentbehrlich zu machen. ${ }^{50}$ Das war die Grundlage der Privilegien der frühhansischen Kaufleute, die nichts anderes waren als hart ausgehandelte Handelsverträge, die dann im Stil der Zeit als herrscherliche Gnadenerweise formuliert wurden. ${ }^{51}$

Die Brückenfunktion, die die hansischen Kaufleute für Europa hatten, war nicht auf den Zwischenhandel beschränkt, den sie selbst aktiv betrieben. ${ }^{52}$ Die transportierten Waren hatten wirtschaftliche Auswirkungen an beiden Enden des Handelswegs, sowohl bei den Erzeugern als auch bei den Verbrauchern. ${ }^{53}$ Denn der hansische Handel transportierte nicht nur

Lübeck offen gelassen wurde; Wolf-Dieter HausCHILD, Frühe Neuzeit und Reformation: Das Ende der Großmachtstellung und die Neuorientierung der Stadtgemeinschaft, in: Lübeckische Geschichte, Lübeck ${ }^{3} 1997$, S. 341-432, hier S. 374f. (mit Lit.); Hans-Jürgen VoGTHERR, Spuren der schwedischen Geschichte im Lübecker Archiv, in: ZVLGA 78, 1998, S. 221-270, bes. S. 249-266.

${ }^{49}$ Dänische Kaufleute z. B. handelten in der ersten Hälfte des 14. Jh.s in den Häfen der Grafschaften Holland und Seeland; SEIFERT, Kompagnons (wie Anm. 40), S. 39 mit Nachweisen; norwegische Kaufleute brachten im frühen 14. Jh. Stockfisch in die Häfen der englischen Ostküste; Arnved NEDKVITNE, Handelssjøfarten mellom Norge og England i høymiddelalderen, in: Sjøfartshistorisk Årbok. Norwegian Yearbook of Maritime History 1976 , Bergen 1977, S. 7-254; DERS., Utenrikshandelen fra det vestafjelske Norge 1100-1600. Bergen 1983 (Typescript), S. 33-61; Terence H. LLOYD, England and the German Hanse. 1157-1611. A Study of their Trade and Commercial Diplomacy, Cambridge 1991, S. 40f.; ein Hinweis auf russischen Direkthandel nach Brügge in HR 1, 7, Nr. 487 14, S. 299 (1422).

${ }^{50}$ Zur Entwicklung des hansischen Handelssystems s. die kurze Zusammenfassung in HaMmel-Kiesow. Hanse (wie Anm. 17), S. 21-38; Ders., Determinanten des Handels zwischen dem Ostseeraum und Niederdeutschland vom 10. bis zum 13./14. Jh., in: Jürgen SARNOWSKY, Burghart SCHMIDT (Hg.), Die Kontinuität der hansischen Dimension im baltischen Raum, Hamburg 2008 (im Druck). - Zu den Absatzmöglichkeiten s. Detlev ELLMERS, Die Entstehung der Hanse, in: HGbll. 103, 1985, S. 3-40, hier S. $26 \mathrm{ff} . ;$ DERS., Die Seehäfen der Hanse als Dienstleistungszentren eines weit gespannten Transportnetzes, in: HGbll. 123, 2005, S. 109-128, hier 109-112.

${ }^{51}$ PITZ, Bürgereinung (wie Anm. 42), S. $304 \mathrm{ff}$.

52 Über den hansischen Zwischenhandel ist bereits viel gearbeitet worden; s. dazu DoLLINGER, Hanse (wie Anm. 25), S. 275-340 und die Nachträge 1998 auf S. 500-508; s. auch LE GoFF, Geburt Europas (wie Anm. 26), S. 162-165, der die „Handelsexpansion“ der hansischen Kaufleute ,beeindruckender' findet als die der Italiener, ebd. 162.

${ }^{53}$ Siehe dazu Franz IRSIGLER, Desiderata einer hansischen Gewerbe- und Produktionsgeschichte, in: Rolf HAMMEL-KIESOW (Hg.), Vergleichende Ansätze in der hansischen Ge- 
Konsumtionsgüter, ${ }^{54}$ sondern in noch größerem Maße Rohstoffe, veredelte Waren und Halbfertigprodukte für die unterschiedlichsten Gewerbe.

Widmen wir uns also im folgenden den Auswirkungen des hansischen Handels auf die gewerbliche Infrastruktur in den Ausgangs- und Zielländern am Beispiel der Versorgung des flandrischen Tuchgewerbes mit den zur Tuchherstellung notwendigen Rohstoffen und veredelten Produkten.

Die Tuchhersteller im westlichen Europa benötigten Wolle, Färbemittel (wie Waid, Wau, Krapp, Chocenille, Safran, Kermesbeeren, Kermesläuse, Brasilholz und später Indigo u. a. m.) sowie Chemikalien (Waidasche, Pottasche, Weinstein, Alaun), Produkte, die in den Produktionsgebieten weit überwiegend importiert werden mussten. Den Import von Wolle aus England nach Flandern besorgten seit Ende des 13. Jahrhunderts zunehmend hansische Kaufleute, ${ }^{55}$ das Färbemittel Waid kam aus dem Niederrheingebiet und aus Thüringen, vor allem aus Erfurt, ${ }^{56}$ aus den preußischpolnischen Waldgebieten, aus dem Baltikum und aus den finnischen Wäldern exportierten hansische Kaufleute Asche nach Flandern, ${ }^{57}$ Alaun brachten italienische Kaufleute aus Kleinasien, ${ }^{58}$ nur Krapp und Wau wurden in den Tuchproduktionsgebieten selbst in großen Mengen angebaut. Die Hanse war somit eingebunden in ein europaweites Zulieferungssystem für eine hoch entwickelte Tuchherstellungsregion, sie war Teil einer diversifizierten Wirtschaft, die in Bezug auf die zur Herstellung notwendigen Materialien eine standortunabhängige Wirtschaftsweise ermöglichte. Von diesen wurden - wie gesehen - nur Krapp und Wau in größeren

schichtsforschung (Hansische Studien: Bd. 13), Trier 2002. S. 209-219; auch SPROEMBERG, Hanse (wie Anm. 23), S. 10, wies darauf hin, dass die Hanse ,die Entwicklung von Gewerben und des Handels bei ihren Handelspartnern in steigendem Maße angeregt" habe.

${ }^{34}$ Siehe dazu unten bei Anm. 83, 84.

55 Wolle war bereits in der ersten Hälfte des 13. Jh.s das Hauptausfuhrprodukt der frühhansischen Kaufleute aus England: Natalie FRYDE, Deutsche Englandkaufleute in frühhansischer Zeit, in: HGbll. 97, 1979, S. 1-14, hier S. 5. Das erste Luibecker Schiff, das in einer der Hafenstädte an der Ostküste Englands überliefert ist, exportierte im Jahr 1275/76 Wolle und Schafsfelle aus Hull; Norman Scott Brien GRAS, The Early English Customs System. A Documentary Study of the Institutional and Economic History of the Customs from the Thirteenth to the Sixteenth Century, Cambridge, Mass. 1918, S. 23, 229f.; T. H. LLOYD, The English Wool Trade in the Middle Ages, Cambridge 1977; zum Wollhandel generell John H. MUNRO, Medieval woollens: textiles, textile technology and industrial organisation, c. 800-1500, in: The Cambridge history of western textiles, ed. by David Jenkins, vol. 1, Cambridge 2003. S. 181-227. hier 186-191.

${ }^{56}$ Astrid SCHMIDT-HäNDEL, Der Erfurter Waidhandel an der Schwelle zur Neuzeit (Europäische Hochschulschriften: Reihe IIV/Geschichte und ihre Hilfswissenschaften 998). Frankfurt u. a. 2004. - Auch in Frankreich und Oberitalien wurde Waid für den Export angebaut.

${ }^{57}$ Siehe dazu unten bei Anm. 68, 71.

${ }^{58}$ Léone Liagre, Le commerce de l'alun en Flandre au Moyen Âge, in: Moyen Âge 61, 1955, S. 177-206. 
Mengen in der Region selbst produziert, ansonsten saß dort ,nur" noch das Herstellungs-know-how: Globalisierung bzw. ,Europäisierung' im Mittelalter. $^{59}$

Welche Dimensionen hatte dieser Handel? Betrachten wir die Sache zunächst von der Seite der Produktion. Allein in den drei großen flandrischen Städten Gent, Brügge und Ypern wurden um die Mitte des 14. Jahrhunderts jährlich rund 80.000 Tuche (mit annähernd 3.200.000 Ellen) hergestellt; zu Beginn des Jahrhunderts müssen es sogar weit mehr gewesen sein, zum Ende hin sank die Anzahl auf rund 30.000 Tuche von allerdings wesentlich höherer Qualität ${ }^{60}$ (was bedeutet, dass mehr und bessere Rohstoffe zur Herstellung pro Tuch benötigt wurden). Neben den drei großen Tuch produzierenden Städten gab es in Flandern noch zahlreiche kleinere Städte, die Exporttuche herstellten, wie die Leie-Städte Kortrijk, Wervik, Menen-Halewijn, Komen und Waasten und im Schelde-DenderBecken Dendermonde, Geraardsbergen, Oudenaarde, Aalst und andere, die am Ende des 14. und zu Beginn des 15. Jahrhunderts 35.000 bis 38.000 Tuche produzierten. ${ }^{6}$ Schlechter überliefert ist die Anzahl der in Westflandern (Aardenburg, Oostburg, Gistel, Diksmuide, Poperingen, Roeselare) und in Nordostflandern (Eeklo, Kaprijke, Axel, Hulst) hergestellten Tuche, die im o. g. Zeitraum auf rund 20.000 jährlich geschätzt wird. ${ }^{62}$ An der Wende des 14. zum 15. Jahrhundert dürften in Flandern somit rund 88.000 Tuche hergestellt worden sein, insgesamt folglich nur ca. 8.000 mehr als ein halbes Jahrhundert früher die drei großen Städte allein produziert hatten. Außerdem lagen in Brabant, Holland und England weitere Tuchproduktionsgebiete.

Es kann also keine Rede davon sein, dass der Bedarf an Rohstoffen erst in einer Zeit zugenommen hätte, als die hansischen Kaufleute ihre beherrschende Stellung im Zwischenhandel zwischen Ost- und Westeuropa bereits verloren hatten. Das Gegenteil ist richtig. Die Nachfrage des 13. und

\footnotetext{
${ }^{59}$ Mit diesem Aspekt der hansischen Geschichte beschäftigte sich dic Sektion des Hansischen Geschichtsvereins auf dem 45. Deutschen Historikertag in Kiel 2004: „Zwischen "Globalisierung" und Konfessionalisierung: Kommunikation und Raum in der hansischen Geschichte". Die Beiträge sind veröffentlicht in HGbll. 123, 2005, S. 1-108; s. dazu unten S. 28-32.

${ }^{60}$ Peter STABEL, „Dmeeste, oirboirlixste ende proffitelixste let ende neringhe“. Een kwantitatieve benadering van de lakenproductie in het laatmiddeleeuwse en vroegmoderne vlaanderen. In: Handelingen der Maatschappij voor Geschiedenis en Oudheidkunde te Gent, Nieuwe reeks - deel li, Gent 1997, S. 113-153, hier 143f. Nach Rolf SPRANDEL, Art. Textilien II. Handel und Gewerbe, in: LexMA Bd. 8, Sp. 598-602, hier Sp. 601, sollen 1313 allein in Ypern 92.500 Tuche mit Plomben versehen worden sein, wobei die Produktion der kleineren Städte im Umfeld mit eingeschlossen war.

${ }^{61}$ STABEL, Een kwantitatieve benadering (wie Anm. 60), S. $144 \mathrm{f}$.

${ }^{62}$ STABEL, Een kwantitatieve benadering (wie Anm. 60), S. 146.
} 
frühen 14. Jahrhunderts dürfte erst im späten 16. oder sogar erst im 17. Jahrhundert wieder erreicht worden sein. ${ }^{63}$ Die Überlieferung zu den einzelnen Handelsgütern weist in die gleiche Richtung. Bereits in der ersten Warenliste des frühhansischen Flandernhandels, einer Utrechter Zollliste des Jahres 1244, zahlten Lübecker und Hamburger Kaufleute Zoll unter anderem für Teer, Pech, Holz und Asche, ${ }^{64}$ gleiches gilt, in der zweiten Jahrhunderthälfte überliefert, für den Englandhandel. ${ }^{65}$ Geradezu paradigmatisch stehen diese Rohstoffe und Veredlungsprodukte des europäischen Nordostens somit am Beginn der Überlieferung zum hansischen Westhandel.

Was lässt sich zur Menge der Importe feststellen? Die Stadt Ypern war um die Mitte des 14. Jahrhunderts für ihre Sayen bekannt, relativ leichte

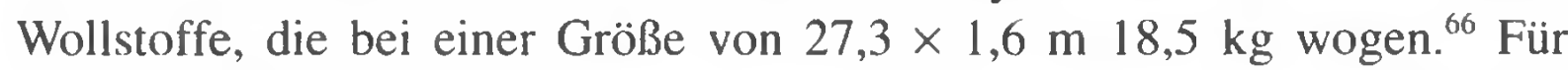
80.000 Tuche dieser Art (es wurden auch weit schwerere hergestellt) hätte man also rund $1.500 \mathrm{t}$ Wolle benötigt. ${ }^{67}$ Hätte man nur die Hälfte der

${ }^{63} \mathrm{Zu}$ den langfristigen Wechsellagen in verschiedenen Sektoren der nordeuropäischen Wirtschaft s. die Zeitreihen des Projekts „Wirtschaftliche Wechsellagen im hansischen Wirtschaftsraum 1300-1800“, die derzeit in die Datenbank „Hansischer Wirtschaftsraum 1300-1800“, Zentralarchiv für Empirische Sozialforschung, Universität zu Köln. Historische Statistik. eingestellt werden, bearbeitet von Barbara FRANZMANN und Rainer METZ, Köln 2005: http: www.histat.gesis/org (letzter Zugriff: 07.09.2007). - Lit. zum lübeckisch-hansischen Bereich Rolf HAMMEL-KIESOW, Häusermarkt und wirtschaftliche Wechsellagen in Lübeck von 1284 bis 1700, in: HGbll. 106. 1988, S. 41-107; DERS., Hansischer Seehandel und wirtschaftliche Wechsellagen. Der Umsatz im Lübecker Hafen in der zweiten Hälfte des 14. Jahrhunderts, 1492-96 und 1680-82, in: Der hansische Sonderweg? Beiträge zur Sozialund Wirtschaftsgeschichte der Hanse, hg. von Michael NORTH und Stuart JENKS (QDhG, N.F., Bd. 39), Köln u. a. 1993, S. 77-93; DERS., Schoßeinnahmen in Lübeck (1424-1811) und Hamburg (1461-1650). Überlegungen zur Interpretation vorindustrieller Zeitreihenl. In: Rolf HAMMEL-KiESOW; Michael HundT (Hg.): Das Gedächtnis der Stadt Lübeck. Festschrift für Antjekathrin Graßmann zum 65. Geburtstag. Lübeck 2005, S. 301-312. - Zu den Problemen. den Umfang des hansischen Handels zu bestimmen s. Peter SPUFFord, The Relative Scale of Medieval Hanseatic Trade. In: HAMMEL-KIESOW: Vergleichende Ansätze (wie Anm. 53), S. 153-162.

${ }^{64}$ Rolf HAMMEL-KIESOW, Lübeck and the Baltic Trade in Bulk Goods 1150-1400, in: Cogs, Cargoes and Commerce: Maritime Bulk Trade in Northern Europe 1150-1400 (Papers in Medieval Studies 15), hg. von Lars BergGren, Nils Hybel, Annette LANDEN, Toronto 2002, S. 53-91; HUB 1, 1876, Nr. 334; siehe auch die Liste der über See im- und exportierten Waren in der Zollrolle von Dordrecht (1287); HUB 1, 1876, Nr. 1033. In der Zollrolle für Brügge und Tourhout bzw. der Maklerrolle für Flandern aus dem Jahr 1252 wurden für z. T. aus dem Hanseraum selbst stammende Wolle, für Waid, Garn und Leinen sowie für die in Brügge gekauften Laken ermäßigte Abgaben bzw. Gebühren festgelegt; ebd., Nr. 432, 436 (Maklerrolle).

${ }^{65}$ HAMMEL-KIESOW, Bulk goods (wie Anm. 64), S. 69-75.

${ }^{66}$ Das sind $0,42 \mathrm{~kg} / \mathrm{m}^{2}$; MUNRo, Medieval woollens (wie Anm. 55), S. 312/13, table 5.7.

${ }^{67}$ Für die Herstellung eines schweren qualitätvollen Wolltuches von 42 Ellen Länge und ca. dreieinhalb Ellen Breite $\left(29,4\right.$ auf 2,45 $\left.\mathrm{m}=72 \mathrm{~m}^{2}\right)$ benötigte man dagegen $38,2 \mathrm{~kg}$ Wolle (MUNRo, Medieval woollens, S. 196f.), das sind 1,88 kg/m², das Viereinhalbfache der überschlägig berechneten Menge der ypernschen Sayen. 
genannten Tuche gebleicht, wären dazu fast $1.000 \mathrm{t}$ Waidasche notwendig gewesen, da man in Flandern $1 \frac{1}{4}$ Pfund Waidasche benötigte, um ein $\mathrm{kg}$ Garn zu bleichen. ${ }^{68}$ Zum Blaufärben der Wolle oder der gewebten Tuche benötigte man Waid und als Katalysator Waid- oder Pottasche, zum Rotfärben Alaun, Weinstcin und Krapp. Mengenangaben dazu, wie viel Pfund der genannten Chemikalien pro Tuch oder pro Mengeneinheit Wolle anfielen, sind äußerst selten überliefert. Beim Gelbfärben z. B. kam ein Kilogramm Wau oder 200-250 g Safran (!), das teuerste Gewürz der Zeit, auf ein Kilogramm Wolle. ${ }^{69}$ Angesichts dieser Überlieferungslage kann man die Importmenge der Färbstoffe und Chemikalien also nicht von den Produktionszahlen her berechnen, sondern muss die (leider sehr seltene und erst spät einsetzende) Überlieferung zu den importierten Mengen heranziehen, um wenigstens eine grobe Vorstellung zu erhalten. ${ }^{70}$ Mengenangaben zur Einfuhr sind erst aus dem 16. Jahrhundert überliefert: In der Mitte des 16. Jahrhunderts importierten die Färber in Utrecht und Geldern jährlich 800-1.000 Last Waidasche, die Amsterdamer Seifensieder jährlich 2.000 Last Waidasche, alle tuchproduzierenden Regionen zusammen also ein Vielfaches davon. Danzig importierte 15832.777 Last Waidasche in 33.324 Tonnen zu je einem Schiffpfund, ${ }^{71}$ so dass man über diese Angabe außerdem einen Einblick in die Einbeziehung des Böttcherhandwerks in den Handel mit Chemikalien aus dem Ostseeraum bekommt. ${ }^{72}$

Was bedeutete das für die Erzeugerländer? Als erstes muss man festhalten, dass viele von den bislang als Rohstoffe klassifizierten Güter des hansischen Handels in Wirklichkeit Gewerbeprodukte waren, die in ihrer Ursprungsregion schon einem komplexen, arbeitsintensiven Aufbereitungsund Veredelungsprozess unterworfen worden waren. Das gilt neben den verschiedenen Arten verarbeiteten Holzes wie z. B. Wagenschot (d. i. astfreies Eichenholz), für Eibenholz, aus dem Bögen hergestellt wurden, für

\footnotetext{
${ }^{68}$ Rolf GELIUS, Waidasche und Pottasche als Universalalkalien für die chemischen Gewerbe des Ostseeraumes im 16./17. Jahrhundert, in: Konrad FRITZE; Eckhard MüLLERMERTENS; Johannes SCHILDHAuER (Hg.), Hansische Studien VII: Der Ost- und Nordseeraum. Politik-Ideologie-Kultur vom 12. bis zum 17. Jahrhundert (Abhandlungen zur Handelsund Sozialgeschichte, Bd. 25), Weimar 1986, S. 91-107, hier S. 99.

${ }^{69}$ Zum Färben generell R. SUNTRUP, Art. Farbe, Fürber, Farbensymbolik, in: LexMA 4, München u. a. 1989. Sp. 285-290.

${ }^{70}$ Für englische Wolle sind die Exportmengen allerdings über Jahrhunderte überliefert; s. dazu nun die Handelsstatistik von England für die Jahre 1278 bis 1509, für manche Exporthäfen bis 1523/24 in, The Enrolled Customs Accounts, calendared by Stuart JENKS, Part I (2004), 2 u. 3 (2005) (List and Index Society vol. 303, 306, 307), Kew 2004, 2005 (die Reihe wird mit jährlich einem Band fortgesetzt).

${ }^{71}$ Alle Angaben nach Gelius, Waidasche und Pottasche (wie Anm. 68), S. 92, 96, 103, $106 \mathrm{f}$.

${ }^{72}$ Rudolf HolBaCH, Hansische Versandlogistik: Das Böttcherhandwerk, in: HGbll. 123, 2005, S. 129-152.
} 
Flachs, für Pech und Teer, aber auch für die uns hier interessierende Waidund Pottasche sowie für Chocenille-Rot. ${ }^{73}$ Über die Art der Organisation dieser Aufbereitungs- und Veredelungsarbeiten ist bislang wenig bekannt; wir wissen nur, dass sie durchgeführt wurden. ${ }^{74}$ Die hansischen Kaufleute regten über die Nachfrage nach diesen aufbereiteten Produkten, die sie befriedigen wollten, in den Erzeugerländern folglich die Produktion und dadurch möglicherweise die Bildung oder den stärkeren Ausbau einer gewerblichen Infrastruktur an. Das muss Produkt für Produkt noch untersucht werden. Die Aschenproduktion z. B. war ein ländlich-bäuerliches Gewerbe, dessen Arbeitsgänge oft in leibeigenschaftsartigen Abhängigkeitsverhältnissen verrichtet wurden. Der Mehrwert floss in die Taschen der Potentaten und regte so allenfalls die Nachfrage nach Luxusprodukten und die Möglichkeiten zur Kriegführung an, nicht aber die gewerbliche Binnenstruktur der Region. ${ }^{75}$ Die Art der Produktion war jedoch vom Stand der örtlichen bzw. regionalen gesellschaftlichen Organisationsform abhängig, nicht von den hansischen Kaufleuten. Diese versuchten selbstverständlich ihre Handelswaren möglichst günstig einzukaufen, um die Gewinnspanne beim Verkauf hochzuhalten. Das war jedoch keine hansische Eigenart, sondern war und ist die Folge jeglichen wirtschaftlichen Handelns, das auf die Erzielung von Gewinn angelegt ist. Je beherrschender die Stellung der hansischen Kaufleute war, d. h. je abhängiger die Produzenten von deren Zwischenhandel waren, desto eher konnte die wirtschaftliche Verbindung sich einem Ausbeutungsverhältnis nähern. Es ist

\footnotetext{
${ }^{73}$ IRSIGLER, Desideratá (wie Anm. 53), S. $216 \mathrm{f}$.

${ }^{74}$ John P. MAARBJERG, Scandinavia in the European world-economy, ca. 1570-1625: some local evidence of economic integration (American University Studies: Ser. 9. History: Vol. 169), New York 1995. S. 30f., lässt den Massenguthandel mit Waldbauprodukten - dem alten, aber falschen Ansatz folgend - zwar erst während des 15. Jh.s beginnen, arbeitet für diesen Zeitraum jedoch die Auswirkungen des steigenden Handelsvolumens auf die Infrastruktur der unterschiedlichen Untersuchungsgebiete sehr differenziert heraus; wie wir oben bei Anm. 64 und 65 bereits sahen, begann der Massenguthandel im Ost-West-Verkehr im nördlichen Europa bereits im 13. Jh.; s. Cogs, Cargoes and Commerce (wie Anm. 64), passim.

${ }^{75}$ Siehe dazu Jake V. Th. KNOPPERS, Roben V. V. Nicholls, Der Ostseeraum und der Welthandel mit Pottasche: Die Bedeutung der Pottasche im Rahmen der chemischen Technologie, 1650-1825, in: Klaus FrIEDLAND, Franz IRSIGLER (Hg.), Seehandel und Wirtschaftswege Nordeuropas im 17. und 18. Jahrhundert, Ostfildern 1981, S. 59-83, hier S. 62-66. In Kleinpolen begünstigten die Aschebrennerei und andere Arten der Waldwarenproduktion im 15. und 16. Jh. die Ausdehnung der Fronwirtschaft; GELIUS, Waidasche und Pottasche (wie Anm. 68), S. 97f'; im 17. Jh. ,verrichteten entweder Leibeigene oder gegen sehr niedriges Entgelt Waldarbeiter" die Aschebrennerei, die in den großen königlichen und Magnaten-Gütern stattfand: Maria BogUCKA, Der Pottaschehandel in der ersten Hälfte des 17. Jahrhunderts, in: Konrad FRITZE; Eckhard MÜLLER-MERTENS; Walter STARK (Hg.): Hansische Studien VI: Autonomie, Wirtschaft und Kultur der Hansestädte (Abhandlungen zur Handels- und Sozialgeschichte, Bd. 23), Weimar 1984, S. 147-152, hier S. 148f.
} 
jedoch sehr schwierig, angesichts der Quellenlage den Grad der tatsächlichen Ausbeutung zu bestimmen. Das Paradebeispiel hansischer Ausbeutung für viele Jahrzehnte, die Abhängigkeit der nordnorwegischen Fischer von den Hansekaufleuten, hat die norwegische Forschung selbst zu den Akten gelegt. Sie betont nun die bedcutende Rolle, die die Hanse bei der Integration Norwegens in die europäische Wirtschaft spielte. ${ }^{76}$

Aus den waldreichen Ländern Ost- und Nordeuropas, aus Preußen und Polen, aus Livland, Russland und aus Skandinavien benötigten, wie gesagt, die tuchverarbeitenden Gewerbe in Flandern Waid- und Pottasche, die als Veredelungsprodukte nach der Verbrennung von Laubholz (überwiegend aus dem bei der Nutzholzgewinnung anfallenden Abfallholz) gewonnen wurden: aus einem Raummeter (Hainbuchen-)Holz etwa ein Kilogramm Pottasche oder 2,7 kg Waidasche. " Die Investitionskosten für die Gewinnung von Waidasche waren allerdings sehr gering. Da alle notwendigen Vorrichtungen aus Holz gebaut werden konnten, entwickelten sich bei ihr keine Zulieferergewerbe. Dieser Schritt setzte erst bei der Weiterverarbeitung zu Pottasche ein, die in großen Kesseln (niederdeutsch ,Pott ${ }^{\text {) }}$ aus Metall eingedampft und anschließend calciniert werden musste; daher der Name ,Pottasche'. Diese Weiterverarbeitung fand im 14. und 15. Jahrhundert in den Städten, vor allem in den Seestädten, statt und verlagerte sich erst im 16. Jahrhundert in die Waldbauregionen. ${ }^{78}$ Für die Herstellung der Waidasche für die o. g. Färber in Utrecht und Geldern waren jährlich zwischen 590.000 und 620.000 Raummeter Holz nötig, für die 2.000 Last Waidasche der Amsterdamer Seifensieder rund 1.240.000 Raummeter, die Danziger Importe waren aus rund 1.725.000 Raummetern Holz gewonnen worden. Das war jedoch nur ein Bruchteil der in den oben angeführten

\footnotetext{
${ }^{76}$ Siehe die zusammenfassende Darstellung von Arnved NEDKVITNE, How important was Hansa Trade for the Norwegian Economy, in: Volker HENN, Arnved NEDKvitnE (Hg), Norwegen und die Hanse. Wirtschaftliche und kulturelle Aspekte im europäischen Vergleich. Frankfurt a. M. u. a. 1994, S. 9-18, hier S. IIff.; Thomas RIIS, Der Einfluss des hansischen Handels auf die Entwicklung der norwegischen Wirtschaft, in: Das Hansische Kontor zu Bergen und die Lübecker Bergenfahrer, hg. von Antjekathrin GRASSMANN (Veröff. zur Geschichte der Hansestadt Lübeck, Reihe B, Bd. 41), Lübeck 2005, S. 28-40.

${ }^{77}$ Zum Holzverbrauch bei der Herstellung von Pottasche s. Rolf GELIUS, Waidasche und Pottasche (wie Anm. 68), S. 92; zur Weiterverarbeitung von Holz- zu Pottasche ebd. S. 96; für die Berechnung des Holzverbrauchs bei der Herstellung von Waidasche danke ich Herrn Gelius herzlich: Für eine Last Waidasche $(1680 \mathrm{~kg})$ müsste der Holzverbrauch ca. 620 Raummeter betragen haben, eher mehr, denn Ausbeuteverluste waren bei der damals unentwickelten Technologie wohl unvermeidlich.

${ }^{78}$ Gelius, Waidasche und Pottasche (wie Anm. 68), S. 96ff.; dort auch zur gewerblichen Organisation der Aschegewinnung seit dem 16. Jh.; zu den teils verheerenden Folgen der Aschegewinnung für die Waldreviere ebd. S. 92f.; bei KNOPPERS, NICHOLLS, Ostseeraum (wie Anm. 75), fehlen Hinweise auf die spätmittelalterliche städtische Produktion und auf die Herstellung in Manufakturen und stadtnahen Fabriken im 17. und 18. Jh.
} 
Tuchproduktionsstädten und -städtchen in Flandern, Brabant, Hennegau, Holland und England benötigten Menge, die Jahr für Jahr in Hunderten von Schiffen in diesen Gewerberegionen angelandet werden mussten. Dort entstand im Tuchgewerbe eine enorm hohe Arbeitsteilung. Aus Flandern selbst liegen $\mathrm{m}$. W. keine genauen Zahlen vor, aber den Geschäftsbüchern des Francesco Datini aus Prato (gest. 1410) lässt sich entnehmen, dass an der Herstellung von 223 Tuchen 1000 Personen beteiligt waren, die 6100 Teiloperationen durchführten. ${ }^{79}$

Weitere Waldbauprodukte der Länder des östlichen und nördlichen Europas, die in den Erzeugerländern aufbereitet wurden, waren außerdem Pech und Teer, unentbehrliche Grundstoffe für den Schiffs- und Hausbau sowie für die Instandhaltung der Schiffe. ${ }^{80}$ Holzteer gewann man durch Schwelung (d. i. trockene Destillation unter Luftausschluss) von Kiefernund Fichtenholz, wobei man seit dem 16./17. Jahrhundert 10-30 Liter Teer je Raummeter Holz gewinnen konnte. Holzpech wiederum entsteht durch Eindampfen von Holzteer in offenen Kesseln, wobei zur Herstellung von $100 \mathrm{~kg}$ Pech ca. $200-400 \mathrm{~kg}$ Teer erforderlich waren, je nach dem ob man von Dick- oder Dünnteer ausging. ${ }^{81}$ Für den späthansischen Zeitraum zwischen 1580 und 1649 hat man eine Handelsaktivität von etwa 8.250 Last Teer und Pech pro Jahr errechnet, das ist eine Gesamtmenge von rund $12.200 \mathrm{t}$ pro Jahr, für deren Herstellung jeweils etwa 1,74 Mio. $\mathrm{m}^{3} \mathrm{Holz}$ benötigt wurden. ${ }^{82}$

Anhand dieser Zahlen lässt sich ungefähr ermessen, wie groß der Arbeitsaufwand bei der Produktion war. Ähnliches gilt für die Herstellung von bearbeiteten Hölzern (Dielenbretter, Fassdauben, Wagenschot u. a. m.), von Flachs, von behauenen Steinen aus Reval u. v. a. m.

Neben der Zufuhr für produzierende Gewerbe wie Tuchherstellung und Schiffbau lieferten die hansischen Kaufleute Konsumtionsgüter. Ihr diversifiziertes Verteilungssystem sorgte dafür, dass in dem von ihnen versorgten Raum prinzipiell sämtliche Handelsgüter der damaligen Zeit auf den Märkten selbst der kleinsten Städte erhältlich waren. ${ }^{83}$ Die hansischen

${ }^{79}$ SPRANDEl, Textilien (wie Anm. 60), Sp. 601.

${ }^{80}$ Rolf Gelius, Teer und Pech im Seehandel der Ostseeländer im letzten Jahrhundert der Hanse (1550-1650), in: HGbll. 120, 2002, S. 181-203, hier S. 185f.; ein Beispicl für die Verwendung: P. Hoffmann, Das Fass und der Teer, in: G. HoffManN, U. Schnall (Hg.), Die Kogge. Sternstunde der deutschen Schiffsarchäologie (Schriften des Deutschen Schiffahrtsmuseums 60), Hamburg 2003, S. 150-153. 1561 kalkulierte man für einen Schiffsneubau von 300 Last Ladekapazität als Korrosionsschutz 2 Last gotländischen Teers (ca. 2.900 kg); Gelius, w. o., S. 185.

${ }^{81}$ Gelius, Teer und Pech, S. 182-185; Pech konnte man auch durch Erhitzen von rohem Kiefernharz gewinnen (ca. $25 \mathrm{~kg}$ aus $100 \mathrm{~kg}$ Harz); ebd.

${ }^{82}$ Gelius, Teer und Pech (wie Anm. 80), S. 203.

${ }^{83}$ Rolf HAMMEL-KIESOW, Wer kaufte die Waren des hansischen Handels? Eine Annähe- 
Kaufleute schufen eine Infrastruktur, die es u. a. ermöglichte, pro Jahr mehr als 200.000 Fässer mit gesalzenem Hering von Schonen, Bohuslän und Aalborg über die Hansestädte bis nach Böhmen, Lwow (Lemberg) und nach Oberitalien zu verschicken, ${ }^{84}$ gleiches geschah mit Stockfisch aus Bergen, mit Öl, tierischen Felten, Wachs und Tuch u. v.a. m. Die niederdeutschen Kaufleute versorgten die Menschen und die Wirtschaft Mitteleuropas mit Gütern in großen Mengen und aus weit entfernten Gegenden. An die Stelle des kleinräumigen Güteraustausches war der Handel mit Waren „aus aller Welt" getreten.

Um diese Nachfrage zu befriedigen beschränkten sich die hansischen Kaufleute jedoch nicht nur auf den Zwischenhandel. In Flandern kam es im Laufe des 15. Jahrhunderts zu engeren Verbindungen mit dortigen Tuchproduzenten. ${ }^{85}$ Die hansischen Kaufleute übernahmen Abnahmegarantien für bestimmte neue Tuchsorten und halfen damit der krisengeschüttelten flandrischen Tuchexportindustrie im 15. Jahrhundert zu Teilen aus der Krise. 1512 bestanden seitens der Hanse Verträge und gegenseitige Verpflichtungen mit sechs Städten und Herrschaften (Poperingen, Dendermonde, Aalst, Menen, Wevik, Tourcoing), „,nach denen die dortigen Drapiers spanische Wolle ausschließlich für die Osterlinge, seulement pour les Osterlincx, verarbeiteten." Die Deutschen übernahmen die komplette Produktion und bezahlten mit Bargeld, wobei der Preis nicht von den einzelnen Kaufleuten, sondern jährlich zwischen Vertretern des Deutschen Kaufmanns in Brügge (= das Kontor zu Brügge) und den Drapiers ausgehandelt wurde. ${ }^{86}$ Nach Hans van Werveke besaßen die Hansen als Abnehmer demnach nicht nur ein Einkaufsmonopol [in Bezug auf die Produktion einzelner Städte], sondern bildeten durch vorherige Preisabsprachen auch ein Einkaufskartell. ${ }^{87}$

Eine Zusammenarbeit hansischer Kaufleute mit fremden nicht niederdeutschen ,Kollegen“, die über reine Warenaustauschgeschäfte (Kauf /

rung an die Endverbraucher, In: »kopet uns werk by tyden«, Beiträge zur hansischen und preußischen Geschichte. Festschrift für Walter Stark, hg. von Nils JÖRN, Detlef KATTINGER. Horst Wernicke. Schwerin 1999, S. 73- 80; Ellmers, Seehäfen (wie Anm. 50), S. $111 \mathrm{f}$.

${ }^{84}$ Carsten JAHNKE, Das Silber des Meeres. Fang und Vertrieb von Ostseehering zwischen Norwegen und Italien - 12.-16. Jahrhundert (QDhG, N.F., Bd. 49), Köln u. a. 2000.

${ }^{85}$ Rudolf HOLBACH, „... seulement pour les Oosterlincx“. Über die Beziehungen zwischen hansischen Kaufleuten und flandrischen Tuchproduzenten. In: Norwegen und die Hanse (wie Anm. 76), S. 73-94, hier S. 80-90; DERS., Frühformen von Verlag und Großbetrieb in der gewerblichen Produktion (13.-16. Jahrhundert.) (VSWG, Beihefte 110), Stuttgart 1994, S. $71-78$.

${ }^{86} \mathrm{HOLBACH}$, ,... seulement", S. $84 \mathrm{f}$.

${ }^{87}$ Hans VAN WERVEKE, Die Stellung des hansischen Kaufmanns dem flandrischen Tuchproduzenten gegenüber. in: Beiträge zur Wirtschafts- und Stadtgeschichte. Festschrift für Hektor Ammann, hg. von Hermann AUBIN u. a., Wiesbaden 1965, S. 296-304, hier 299; zitiert nach HOLBACH, ,... seulement“ (wie Anm. 85), S. 85 Anm. 84. 
Verkauf) hinausgingen, war bislang kaum Thema der Forschung. Verbote des Handels mit Butenhansen (= außerhalb der Hanse stehende Personen), die neben der Gästefeindlichkeit als Beweis für die Abgeschlossenheit nach außen galten, sind jedoch inzwischen als zeitlich befristete Maßnahmen im Vorfeld und im Verlauf von handclspolitischen Auseinandersetzungen erkannt worden, wie übrigens auch der größte Teil der Kreditverbote. ${ }^{88}$ Eine Aufgabe der hansischen Geschichtsforschung ist es daher, die Kontakte zu außerhansischen Kaufleuten und anderen Zulieferern vorurteilsfrei unter die Lupe zu nehmen und Handelsgesellschaften zwischen Hansen und Butenhansen in den Quellen zu suchen. ${ }^{89}$ Dabei gilt freilich, dass solche Gesellschaften nicht Selbstzweck waren, sondern den jeweiligen Partnern Erfolg versprechen mussten. ,Internationalität' als Selbstzweck war und ist kein wirtschaftliches Kriterium.

Zwei Beispiele längerfristiger, internationaler' Zusammenarbeit (d. h. mit Partnern, die nicht zur Hanse gehörten) in der Form gemeinsamen Handels sind bislang bekannt. Das erste Beispiel gehört in die Formationszeit der Hanse und ist daher mehr als Beispiel zu werten, was vor der Zeit der an Städte gebundenen hansischen Handelsorganisation möglich war, das zweite Beispiel gehört ins 15. Jahrhundert, also in die Zeit der voll ausgebildeten hansischen Organisation.

Die Insel Gotland war im 12. Jahrhundert das Zentrum des Ostseehandels. Da die Schifffahrt bis weit ins 14. Jahrhundert hinein die Küstenschifffahrt bevorzugte und die Fahrt übers offene Meer möglichst vermied. hatte die Insel eine handelsstrategisch günstige Lage. Die gutnischen Kaufleute dominierten den lukrativen Russlandhandel mit Pelzen und Wachs, und Gotland selbst war zudem Treffpunkt russischer, schwedischer, dänischer und in zunehmender Zahl deutscher Kaufleute geworden. Nachdem es vor 1161 zu blutigen Auseinandersetzungen zwischen Gotländern und Deutschen gekommen war, einigten sich beide Seiten und räumten sich gegenseitig die gleichen Rechte im jeweiligen Gastland ein. 1 191/92 sandte diese Kaufleutegemeinschaft einen Boten, den Gotländer Arbud (Herbord), zum Abschluss eines Handelsvertrages zu dem Fürsten von Novgorod, der diesen Zusammenschluss von Kaufleuten unterschiedlicher ethnischer Herkunft offensichtlich als Gemeinschaft anerkannte, wie später auch der englische König. ${ }^{90}$ Das heißt, dass sich deutsche und

${ }^{88}$ Stuart JENKS, Zum hansischen Gästerecht, in: HGbll. 114, 1996, S. 3-60, hier 53ff.; DERS., War die Hanse kreditfeindlich? In: VSWG 69, 1982, 305-338.

${ }^{89}$ Siehe dazu die zahlreichen Hinweise auf Handelsgesellschaften zwischen Hansen und Butenhansen in JENKS, Gästerecht (wie Anm. 88), S. 53 ff.

${ }^{90}$ Detlef KATTINGER, Die Gotländische Genossenschaft. Der frühhansisch-gotländische Handel in Nord- und Westeuropa (QDhG N.F. Bd. 47), Köln u. a. 1999, S. 147-149 (zu Novgorod), 184f., 237-266, zusammenfassend 262ff. (zu England) 
gutnische Kaufleute auf Gotland in einer Gemeinschaft zusammenschlossen, die gilda communis, auch universitas mercatorum bzw. im Westen omnes mercatores de Gutlandia genannt wurde. ${ }^{9 \mid}$ Der Zusammenschluss zu einer universitas war die konsequente rechtliche Folge einer Handelspraxis, bei der gutnische Kaufleute ihre niederdeutschen Handelspartner zunächst von Gotland mit nach Novgorod nahmen, zuerst wohl auf gutnischen Schiffen, später dann im gemischten Flottenverband. Die Zusammenarbeit war für beide Seiten anscheinend derart erfolgreich (vermutlich stellte die eine Seite die Schiffe, die andere die Verbindungen zu den enorm aufnahmefähigen Märkten im mittleren und westlichen Europa), ${ }^{92}$ so dass sie vermutlich auch auf den Handel nach Norwegen, gesichert auf den Handel nach England und in Bezug auf die gutnischen Kaufleute Visbys auf Flandern ausgedehnt wurde..$^{93}$ Diese Gemeinschaft gutnischer und niederdeutscher Kaufleute, ein tatsächlich ,internationaler ${ }^{6}$ Zug der frühhansischen Geschichte, fand nach der Mitte des 13. Jahrhunderts ein Ende, im Ostseehandel etwas früher als in England. Der Grund war nicht ethnischer oder „sozialer" Natur (der Art, dass man die „Bauernhändler“, die nicht in Visby, sondern im ländlichen Bereich der Insel wohnten, nicht mehr als gesellschaftlich gleichrangig anerkannt hätte), sondern die Tatsache, dass in der damals entstehenden Handelsorganisation der Städte die auf dem Land sitzenden („Bauern-“)Kaufleute nicht durch jurisdiktionelle und exekutive Maßnahmen der Städte kontrolliert werden konnten. Sie bildeten somit einen Unsicherheitsfaktor in dem durch vielseitige Handelsverträge, Geleits- und Beistandsabkommen entstehenden System der frühen Hanse, der ausgeschlossen werden musste, um gegebenenfalls über Sanktionen die Einhaltung der geschlossenen Verträge erzwingen zu können. ${ }^{94}$ Aus dem gleichen Grund wurden rund 100 Jahre später die holländischen Kaufleute, die nicht Bürger einer Hansestadt waren, von den schonenschen Messen ausgeschlossen. ${ }^{95}$

Das zweite Beispiel: Im 15. Jahrhundert lassen sich sehr enge Verbindungen zwischen Kölner Englandfahrern und Londoner Mercers erkennen. Die beiden Gruppen hatten einen Waren- und Wechselkreislauf aufgebaut, „wobei die Hansen Warenschulden für den Erwerb von Tuch bei den Mercers in London machten, die per Wechsel auf den Brabanter Messen rückzahlbar waren. Die Mercers wiederum repatriierten die Erträge, die ihre hansischen Handelspartner ihnen auf der Messe auszahlten, indem sie das

\footnotetext{
${ }^{91}$ KATTINGER, Gotländische Genossenschaft, S. 175-181.

${ }^{92}$ HAMMEL-KIESOW, Determinanten (wie Anm. 50).

${ }^{93}$ KATTINGER, Gotländische Genossenschaft (wie Anm. 90), S. 335-343 zu Flandern.

${ }^{94}$ KATTINGER, Gotländische Genossenschaft (wie Anm. 90), S. 340.

${ }^{95}$ SEIFERT, Kompagnons (wie Anm. 40), S. 90-92.
} 
in Brabant eingenommene Geld an andere Kaufleute (in der Regel Landsleute) liehen. die Messewechsel erwerben und nach England exportieren wollten". ${ }^{96}$ Dieser Waren- und Wechselkreislauf scheint seit den 1420er Jahren bestanden zu haben. Die Kooperation zwischen beiden Gruppen umfasste auch die Schiffe, da sowohl die Kölncr Englandfahrer als auch die Londoner Mercer in der Regel dieselben (seeländischen) Schiffe für den Transport ihrer Waren nach und von den Brabanter Messen benutzten. Insgesamt kann man den Schluss ziehen, dass die Mercers die Kölner nicht als Konkurrenten, sondern vielmehr als Partner betrachteten. ${ }^{97}$ Während der Verhansung der Kölner, d. h. in der Zeit, als die Kölner Kaufleute vom Gebrauch der hansischen Privilegien ausgeschlossen waren, brachten deren Londoner Geschäftsfreunde das Tuch der Kölner auf fremde Rechnung ganz offensichtlich zu den Messen. Nach der Aufhebung der Verhansung war dieses Verfahren nicht mehr notwendig. ${ }^{98}$

Solche internationalen" Aspekte fanden sich bislang jedoch nur im Außenhandelsbereich der hansischen Kaufleute. Ihren eigenen Raum schotteten die Hansen $a b$, indem sie fremde Kaufleute zu ihren Netzwer$k^{49 y}$ seit dem späten 13. und 14. Jahrhundert nur dann zuließen, wenn sie das Bürgerrecht einer Hansestadt annahmen (also keine ,Fremden' mehr waren). ${ }^{100}$ Dass das keine prinzipielle Fremdenfeindschaft war, sondern die oben bei dem gemeinsamen Handel mit den Gotländern erörterte Möglichkeit des rechtlichen Zugriffs bei Verstößen gegen das städtische Recht (in das hansische Beschlüsse immer umgesetzt werden mussten) ${ }^{101}$ das

\footnotetext{
${ }^{96}$ Stuart JENKS, England und die kontinentalen Messen im 15. Jahrhundert und die Entstehung der Merchant Adventurers, in: Peter JOHANEK, Heinz STOOB (Hg.), Europäische Messen und Märktesysteme in Mittelalter und Neuzeit (Städteforschung A/39), Köln u. a. 1996, S. $66 f$.

${ }^{97}$ JENKS, England und die kontinentalen Messen, S. 68.

${ }^{98}$ Stuart JENKS , England, die Hanse und Preußen: Handel und Diplomatie; 1377-1474 (QDhG, N.F.. Bd. 38, Teile 1-3), Köln u. a. 1992, S. 186-190.

${ }_{99}$ Zur Netzwerkstruktur des hansischen Handels, auch eines der historischen Phänomene, die erst durch die ,lebensweltliche Erfahrung' (s. o. bei Anm. 46) mit Netzwerken in der heutigen internationalen Wirtschaft erkannt wurden, s. Stephan SELZER; Ulf Christian EWERT, Verhandeln und Verkaufen. Vernetzen und Vertrauen. Über die Netzwerkstruktur des hansischen Handels, in: HGbll. 119, 2001, S. 135-162; DIES.. Die Neue Institutionenökonomik als Herausforderung an die Hanseforschung. in: HGbll. 123, 2005, S. 7-29; JAHNKE, Carsten, Netzwerke in Handel und Kommunikation an der Wende vom 15. zum 16. Jahrhundert am Beispiel zweier Revaler Kaufleute, Habil. masch., Kiel 2004: Ders., Geld, Geschäfte, Informationen. Der Aufbau hansischer Handelsgesellschaften und ihre Verdienstmöglichkeiten (Handel, Geld und Politik 10), Lübeck 2007; s. zukünftig Mike BURKHARDT, Die Geschichte des Bergenhandels im Spätmittelalter - Handel. Kaufleute. Netzwerke, Diss. phil. Universität Kopenhagen (in Vorbereitung zum Druck).

${ }^{100}$ Siehe dazu aber die Hinweise auf Handelsgesellschaften zwischen Hansen und Butenhansen in JENKS, Gästerecht (wie Anm. 88), S. $53 \mathrm{ff}$.

${ }^{101}$ Siehe dazu oben bei Anm. 94,95 .
} 
zugrunde liegende Kriterium war, zeigen die Einbürgerungen von Slawen und Skandinaviern in Rostock ${ }^{102}$ ebenso wie der Nürnberger Kaufleute in Lübeck im 15. und 16. Jahrhundert, die - wie Matthias Mulich - den Handel ihrer oberdeutschen Verwandtschaft auf diesem Wege durch die Vorteile bereicherten, die sich aus den lübisch-hansischen Privilegien gewinnen ließen. ${ }^{103}$ Konkurrenz, die sich nicht einbinden ließ, wurde, wenn man es vermochte, mit allen Mitteln bekämpft, wofür als Beispiel das Schicksal der Engländer in den preußischen Städten stehen mag.

Um diese weit gespannten Handelsbeziehungen aufzubauen, zu sichern und aufrecht zu erhalten, entwickelten die Fernkaufleute und die Räte der Hansestädte eine Diplomatie, die bereits im 13. Jahrhundert internationalen europäischen Zuschnitt hatte und im Jahr 1648 bei dem Westfälischen Friedenswerk ihren verfassungsrechtlichen Höhepunkt erreichte. Sie wurde getragen von Unterhändlern wie dem Lübecker Ratsherrn Johan von Dowaye. genannt nach der Stadt Dowaye an der flämisch-französischen Sprachgrenze, aus der er möglicherweise stammte. Er ist der erste dieser Diplomaten, von dem Schreiben überliefert sind, die seine psychische Verfassung wegen der Dauerbelastung, der er zwischen 1280 und 1303 ausgesetzt war, zum Ausdruck bringen. Zunächst war er zu diplomatischen Verhandlungen in Brügge, schlichtete anschließend einen Streit zwischen dem Grafen von Flandern und spanischen Kaufleuten, fuhr zum dänischen König nach Helsingborg, anschließend nach Reval, wurde bereits auf der Rückfahrt nach Lübeck - von Visby aus wieder nach Reval zurückbeordert, war später als Gesandter in Bergen beim norwegischen König und schließlich in Örebro beim schwedischen König. ${ }^{104}$ Um seine und die Leistungen anderer hansischer Diplomaten zu würdigen, muss

${ }^{102}$ Silke JASTER, Die Nichtdeutschen in Rostock im 13. und 14. Jahrhundert (Rostocker Studien zur Regionalgeschichte. Bd. 4), Rostock 2001, z. B. S. 365 f.: mit dieser Arbeit wird der Ansatz aufgegriffen, den bereits Paul JOHANSEN, Umrisse und Aufgaben der hansischen Siedlungsgeschichte und Kartographie, in: HGbll. 73, 1955, 1-105. hier S. 21-31 (Zusammenschlüsse fremder Kaufleute und Gäste in den Hansestädten) einforderte.

${ }^{103}$ Fritz RöRIG, Das Einkaufsbüchlein der Nürnberg-Lübecker Mulichs auf der Frankfurter Fastenmesse des Jahres 1495. in: DERS.. Wirtschaftskräfte im Mittelalter. Abhandlungen zur Stadt- und Hansegeschichte (2. durchgesehene und ergänzte Auflage), hg. von Hans KAEGBEIN. Wien u. a. 1971, S. 288-350; Gerhard FOUQUET, Geschäfte und Politik. Ehe und Verwandtschaft - Briefe an den Nürnberg-Lübecker Kaufmann Matthias Mulich vom Winter 1522/23, in: V. H. BrÄUER, E. SCHLENKRICH (Hg.), Die Stadt als Kommunikationsraum (Beiträge zur Stadtgeschichte vom Mittelalter bis ins 20. Jahrhundert. Festschrift für Karl Czok zum 75. Geburtstag). Leipzig 2001. S. 311-346.

${ }^{104}$ STOOB, Hanse und Europa (wie Anm. 22), S. 5 f.; Detlef KATTINGER, Johann von Douai - ein hansischer Diplomat des 13. Jahrhunderts, in: Detlef KATTINGER: Horst WeRniCKE. Ralf-Gunnar WeRliCH (Hg.): Akteure und Gegner der Hanse - Zur Prosopographie der Hansezeit [Konrad - Fritze - Gedächtnisschrift] (Hansische Studien IX / Abhandlungen zur Handels- und Sozialgeschichte, Bd. 30), Weimar 1998, S. 25-36. 
man nicht immer den Stoßseufzer des englischen Gesandten Dr. Russel bei den Friedensverhandlungen in Utrecht 1474 über die herausragende hansische Diplomatie zitieren. ${ }^{105}$ Es genügt $\mathrm{m}$. E. sich ins Gedächtnis zu rufen, dass die Hanse unter sich seit Mitte des 14. Jahrhunderts zunehmend zu ihren Ungunsten entwickelnden Bedingungen bis gegen Ende des 17. Jahrhunderts Bestand hatte.

Neben den wirtschaftlichen und machtpolitischen Strukturen veränderten sich auch die Gepflogenheiten des diplomatischen Verkehrs. ${ }^{106}$ Während im 14. Jahrhundert der dänische König Waldemar II. noch persönlich und ohne Beisein seiner Räte mit den hansischen Ratsendeboten verhandelte, war die herrscherliche Politik gegenüber den Städten seit dem 15. Jahrhundert mehr und mehr rechtsbetont. Die hansischen Städtevertreter mussten nun studierte Juristen, d. h. römisch-rechtlich geschulte Gesandtschaftsmitglieder an die Höfe mitnehmen. Trotz der von den westlichen Kronräten und Gesandten betonten juristischen Überlegenheit, ${ }^{107}$ gelang es den hansischen Diplomaten, ihren Verhandlungspartnern jeweils so große Gegenleistungen im Handelsbereich zu bieten, dass es trotz aller Auseinandersetzungen z. B. im Falle Englands bis zum Jahr 1598 immer wieder zu Privilegienbestätigungen - wenn auch in unterschiedlicher Form kam. Welche Bedeutung die Hansestädte, trotz aller immer wieder vorgebrachten Klagen über zu hohe Kosten, dem diplomatischen Verkehr beimaßen, verdeutlicht auch die berufliche Tätigkeit des Syndicus' der Hanse, des Kölner Juristen Heinrich Sudermann, der insgesamt 14 seiner 35 Amtsjahre zwischen 1556 und 1591 auf diplomatischen Reisen zwischen England und Polen verbrachte. Nur Bergen und Novgorod besuchte er nicht, vielleicht weil er die dort gesprochenen Sprachen nicht beherrschte. Er ist außerdem ein Beispiel für die ,innere Diplomatie' in der Hanse, da er als Katholik im Kreis der Ratsherren und Bürgermeister, die meist strenggläubige Lutheraner waren, reibungslos wirken konnte. ${ }^{108}$

\footnotetext{
${ }^{105}$ Dr. Russel soll gesagt haben, dat he lever myt alle der werlde forsten denne myt den radessendeboden wolde dedingen, dass er lieber mit allen Fürsten der Welt als mit (hansischen) Ratssendeboten verhandeln wolle; HR II, 7, Nr. 138, § 100, S. 265.

${ }^{106}$ Thomas BEHRMANN. Herrscher und Hansestädte. Studien zum diplomatischen Verkehr im Spätmittelalter (Greifswalder Historische Studien, Bd. 6), Hamburg 2004.

${ }^{107}$ Die eigentliche Differenz lag zwischen dem einungsrechtlichen Denken der hansischen Ratsendeboten und der römisch-rechtlichen Argumentation der gelehrten Räte der westeuropäischen Reiche und Fürstentümer, am Beispiel der Trennung von äußerer Form und Inhalt beim gemeinrechtlichen Begriff der Vollmacht erläutert von PITZ, Bürgereinung (wie Anm. 42), S. 418-422.

${ }^{108}$ STOOB, Hanse und Europa (wie Anm. 68), S. 11 f.; Herbert LANGER, Gestalten der Spätzeit: Die Syndici der Hanse, in: Akteure und Gegner (wie Anm. 104), S. 219-230, hier 219-227.
} 
Schließlich gelang es den Hansestädten unter der Führung des Lübecker Syndicus und späteren Bürgermeisters der Stadt, David Gloxin, die civitates Anseaticae in Artikel XVII $\$ 10$ und 11 des Osnabrücker Friedensinstrumentes von kaiserlicher und schwedischer Seite in das Westfälische Friedenswerk einschließen zu lassen. Art. $\mathrm{X} \S 10$ billigte auch denjenigen Hansestädten, die durch den Friedensvertrag unter schwedische Landeshoheit fielen (Wismar, Stralsund, Greifswald), freien Handel und Schifffahrt inner- und außerhalb des Reiches zu. Die Einbeziehung der Hansestädte in den Friedensschluss und ihre zum ersten mal erfolgte Nennung in einem Verfassungsdokument des Reiches waren ein großer Erfolg der hansischen Diplomatie. Die Abgesandten der drei Städte Lübeck, Bremen und Hamburg traten dabei nicht nur für ihre eigenen Belange, sondern tatsächlich für alle noch verbliebenen Hansestädte ein. Allerdings erfolgte dieser Durchbruch zur verfassungsrechtlichen Anerkennung zu spät. Das Ende des Dreißigjährigen Krieges als „Staatshildungs-Krieg“ entzog mit der Konsolidierung der großen Territorien im Nord- und Ostseeraum der Hanse als Verbindung freier Städte die weitere Existenzmöglichkeit. Zwar versuchte man in den 50er und 60er Jahren des 17. Jahrhunderts den größeren Hanseverbund wieder herzustellen. doch ein letzter Versuch mit dem Hansetag in Lübeck im Jahr 1669 versammelte die Ratssendeboten von nur noch sechs Städten - drei weitere hatten Vollmachten erteilt - und ging mit einem Rezess ohne wirklichen Beschluss zu Ende. ${ }^{109}$

\section{Reflexiver Ansatz: Hanse, Globalisierung und Europäische Union}

Heutzutage können wir wesentliche Organisationsmerkmale der Hanse wahrscheinlich besser verstehen als frühere Generationen. Zum ersten, weil wir nicht mehr - wie in der Hochzeit des bürgerlichen Nationalstaates - in Kategorien hierarchisch aufgebauter Staaten und weitgehend geschlossener Nationalwirtschaften denken. Die zunehmende weltweite internationale Integration von Güter-, Kapital- und Arbeitsmärkten im Zeitalter der Globalisierung macht(e) den Blick frei für die Leistung der hansischen Kaufleute bei der Integration bis dahin peripherer Regionen nach Mittel- und Westeuropa.

Zum zweiten erleben wir, ebenfalls in den letzten drei Jahrzehnten verstärkt. dass curopäische Staaten einerseits Souveränitätsrechte an eine überstaatliche Organisation, die Europäische Union, abtreten, andererseits aber auf zentralen Handlungsfeldern ihre Souveränität wahren. Das schärft

\footnotetext{
${ }^{109}$ Rainer Postel, Zur ,erhaltung dern commercien und darüber habende privilegia“. Hansische Politik auf dem Westfälischen Friedenskongreß, in: Heinz DuCHARDr (Hg.), Der Westfälische Friede (HZ, Beiheft 26), München 1998, S. 523-540.
} 
den Blick für die Gemengelage unterschiedlicher Arten von Autonomie zur Zeit der Hanse, die im Zeitalter der absoluten Hochschätzung des souveränen Staats mit obrigkeitlicher Struktur nur schwer ,denkbar' war.

\section{Hanse und Globalisierung}

Zunächst zum Verhältnis von Hanse und Globalisierung. Gibt es strukturelle Ähnlichkeiten zwischen beiden? Unter Globalisierung versteht man Prozesse einer zunehmenden internationalen Verflechtung verschiedenster Bereiche unserer Erde. Sie betreffen einzelne Menschen, Gesellschaften, Institutionen und Staaten und sie finden in den Bereichen der Wirtschaft, Politik, Kultur, Umwelt, Kommunikation u. a. m. statt. Als wesentliche Ursachen der Globalisierung gelten die wachsende internationale Mobilität von Gütern und Produktionsfaktoren, die wiederum aufruht auf technischem Fortschritt, insbesondere im Transportwesen und in der Kommunikation, sowie auf politischen Entscheidungen zur Liberalisierung des Welthandels bzw. von „Verdrängungen der staatlichen Wirtschaftspolitik". ${ }^{110}$ Historisch gesehen ist die gegenwärtig ablaufende Globalisierung Teil eines im Prinzip seit Jahrtausenden, verstärkt seit etwa 500 Jahren ablaufenden Prozesses von Aufbau, Verdichtung und zunehmender Bedeutung der Vernetzung im lokalen, regionalen und schließlich weltweiten Rahmen. Das war kein kontinuierlicher Prozess, sondern eher eine Abfolge von ,"Globalisierungsanläufe[n]“, die aber stets irgendwann einmal abbrachen. Daher kann man sie als ,Vorgeschichte“ der Globalisierung betrachten"."11

Die hansische Geschichtsforschung hat sich mit diesem Phänomen auf dem 45. Deutschen Historikertag in Kiel 2004 auseinander gesetzt. „Zwischen ,Globalisierung " und Konfessionalisierung: Kommunikation und Raum in der hansischen Geschichte" war das Thema der Sektion des Hansischen Geschichtsvereins. ${ }^{12}$ Wir stellten die Frage, ob in der Betrachtung

${ }^{110}$ Osterhammel. Petersson, Globalisierung (wie Anm. 27), S. 10-15; s. auch Knut BORCHARDT, Globalisierung in historischer Perspektive (Sitzungsberichte der Bayerischen Akademic der Wissenschaften Jg. 2001, Heft 2), München 2001: Richard TILLY. Globalisierung aus historischer Sicht und das Lernen aus der Geschichte. Köln 1999. S. 9. definiert Globalisierung als die ,zunehmende internationale Integration von Güter-. Kapital- und Arbeitsmärkten. unmittelbar verursacht durch wachsende internationale Mobilität von Produkten und Produktionsfaktoren, zumindest mittelbar getragen vom technologischen Wandel und von Verdrängungen der staatlichen Wirtschaftspolitik".

${ }^{111}$ Osterhammel, Petersson, Globalisierung (wie Anm. 27), S. 25: O. und P. folgen Wallersteins Ansatz, der mit dem Aufbau der spanischen und portugiesischen Kolonialreiche in der Zeit um 1500 den Beginn einer im Prinzip irreversiblen weltweiten Vernetzung ansetzt; ebd.

${ }^{112}$ Siehe dazu Albrecht CORdES, Antjekathrin Grassmann und Rolf HaMmEL-Kiesow, 
der hansischen Geschichte unter dem Aspekt der Globalisierung mehr liege als nur eine erneute historisch problematische Aktualisierung nach der deutschnationalen Überhöhung, die bis 1945 das Bild bestimmte, und dem seit dem bis heute beliebten Blick auf die Hanse durch eine europäische Brille? Wir haben das dahingehend beantwortet, dass die Übertragung des Begriffs Globalisierung auf vergleichbare Prozesse der Vergrößerung und Verdichtung von Wirtschaftsräumen in der Vergangenheit auf Grund der strukturellen Ähnlichkeiten der Prozesse und der sie auslösenden und begleitenden Faktoren durchaus möglich ist.

Wenn man unter Globalisierung die Intensivierung und Beschleunigung grenzüberschreitender Transaktionen bei deren gleichzeitiger räumlicher Ausdehnung versteht, so ,globalisierten 'bzw. ,europäisierten' die Aktivitäten der hansischen Kaufleute zweifellos das nördliche Europa. Das Gleiche gilt für die Gründe, die für die Globalisierung verantwortlich gemacht werden, nämlich die wachsende internationale Mobilität von Gütern und Produktionsfaktoren und die technischen Entwicklungen besonders im Bereich von Transportwesen und Kommunikation. Sie haben, wie wir oben am Beispiel der flämischen Tuchindustrie bereits gesehen haben der englische Schiffbau wäre ein weiteres - die Standortgebundenheit von gewerblichen Zentren aufgehoben. ${ }^{113}$ Außerdem gibt es eine Reihe von weiteren Punkten, in denen der hansische Handel über die Rechtsgrenzen der Städte und Länder hinweg dem heutigen globalen und oft kritisierten Wirtschaftleben ähnelt. Das betraf die Chance, dank eines effektiven Informationsaustausches sowie billiger und relativ zuverlässiger Transportmittel und -wege Preisgefälle auszunutzen, das betraf auch die z. T. sehr erfolgreichen Ansätze zur Standardisierung von Maßen und Währungen wie auch von rechtlichen Institutionen, die Schaffung von stabilen Rahmenbedingungen einschließlich effektiver Rechtsverfolgungs- und Vollstreckungsmöglichkeiten, ${ }^{1 / 4}$ besonders deutlich ausgeprägt in den Ansätzen einer überterritorialen Standardisierung des Seerechts. Das Hansische oder auch Hanseatische Seerecht in seiner Fassung von 1614 war das

Zwischen ,Globalisierung " und Konfessionalisierung: Kommunikation und Raum in der hansischen Geschichte. Einleitende Bemerkungen zur Sektion des Hansischen Geschichtsvereins auf dem 45. Deutschen Historikertag in Kiel 2004, in: HGbll. 123, 2005, S. 1-6. Der Historikertag hatte das Generalthema „Kommunikation und Raum".

${ }^{113}$ Siehe oben S. $15 \mathrm{ff}$.

${ }^{114}$ Literatur in Auswahl: Angelo PICHIERRI, Die Hanse - Staat der Städte. Ein ökonomisches und politisches Modell der Städtevernetzung (Stadt, Raum und Gesellschaft: Bd. 10), Opladen 2000: Stephan SELZER; Ulf Christian EWERT, Die Neue Institutionenökonomik als Herausforderung an die Hanseforschung, in: HGbll. 123, 2005, S 7-29; Stuart JENKS, Transaktionskostentheorie und die mittelalterliche Hanse, in: ebd., S. 32-42; Christina LINK, Diana KAPFENBERGER, Transaktionskostentheorie und hansische Geschichte: Danzigs Seehandel im 15. Jahrhundert im Licht einer volkswirtschaftlichen Theorie, in: ebd., S. 153-170. 
größte und zugleich das letzte bedeutende Gesetzgebungswerk der Hanse und fand bis ins 19. Jahrhundert hinein vor den Gerichten der Seehandelsstädte Anerkennung. Formell wurde es erst durch das Allgemeine Deutsche Handelsgesetzbuch von 1861 außer Kraft gesetzt. ${ }^{115}$

Zwar gab es auch Unterschiede wie z. B. die Tatsache, dass es im hansischen System kaum Ansätze zu rechtlich verfassten Handelshäusern gab, andererseits können die Kooperationsformen hansischer Kaufleute durch die betriebswirtschaftlichen Modelle der modernen Netzwerktheorie von Unternehmen erklärt und die Organisationsform des hansischen Handels als historische Netzwerkform definiert werden. ${ }^{116}$ Auch das Problem, dass sich die Hanse über den reinen Tauschhandel hinaus der Kooperation mit Nichthansen tendenziell eher verschlossen habe und in diesem Sinne gerade nicht ,global ' im Sinne von ,grenzenlos' gedacht habe, wurde oben mit dem Hinweis auf die nachgewiesenen bzw. erschließbaren Handelsgesellschaften zwischen hansischen Kaufleuten und Butenhansen bereits angesprochen. Hier scheint mir eher eine Forschungslücke als eine grundsätzliche Abschottung vorzuliegen. ${ }^{117}$

Die Intensität des grenzüberschreitenden, über Städte und Länder hinausgreifenden Handels und der durch ihn angestoßenen wirtschaftlichen und kulturellen Verbindungen wäre demnach ein gemeinsames Kennzeichen des Europas der Hansezeit und - weltweit - des heutigen Zeitalters der Globalisierung; sie wäre damit zugleich ein Unterscheidungsmerkmal

${ }^{115}$ Götz LANDWEHR. Das Seerecht der Hanse (1365-1640), Hamburg 2003, S. 143-148 für die Zeit des 17.-19. Jh.s.

${ }^{116}$ SELZER, EWERT, Verhandeln und Verkaufen (wie Anm. 99), S. 135-162.

${ }^{117}$ Siehe oben S. 22 ff. mit Anm. 100. Die unterschiedliche Bewertung von Handelsgesellschaften mit Butenhansen lag möglicherweise auch an den unterschiedlichen Interessen der beiden Kaufleutegruppen, die den kaufmännischen Kern der Hanse bildeten. Zum einen die Mehrheit mittlerer und kleiner Fernhändler, auf deren Einfluss wohl ein großer Teil der gästerechtlichen Bestimmungen, Verbote des Transitverkehrs und Klagen gegen Monopolbestrebungen zurückzuführen sind, und der sehr viel kleineren Gruppe finanzkräftiger Kaufleute, die z. B. den risikoreicheren, aber gewinnträchtigen Westhandel mit Anbindung an die neue atlantische Wirtschaft im Auge hatten; HAMMEL-KIESOW, Hanse (wie Anm. 17), S. 106-109; s. dazu nun auch den Ansatz von Friedrich Bernward FAHLBUSCH. Zwischen öffentlichem Mandat und informeller Macht: Die hansische Führungsgruppe, in: HGbll. 123. 2005, S. 43-60, der den Erfolg des hansischen Verbandes auf das Wirken einer informellen Führungsgruppe zurückführt, die dreifach homogen gewesen sei: ,.in ihrer politisch-sozialen Position, in ihren wirtschaftlichen Interessen und in ihrer elitären Identität. Diese Gruppe nutzte subsidiär und sekundär die den Zeiten entsprechenden Rechtsmaterien und Organisationsformen und ermöglichte somit Existenz und Funktionieren des Verbandes. Diese Art Gruppe soll mit dem Begriff „Amigonat" belegt werden, um alle sich überlagernden, gegenseitig beeinflussenden Arten von in Verwandtschaft, Freundschaft, Geschäftspartnerschaft und politisch-sozialen Ämtern begründeten Bezichungen, um die diffuse Vermischung öffentlich-offizieller Amtsinhabe, informeller Machthabe und persönlicher Interessen zu erfassen. [...] Als dieses Substrat städtischer Führungsgruppen bessere Wege zum Vollzug eigenen Interesses [fand, ließ] es den Organisationsrahmen Hanse still verfallen" (cbd. 59). 
gegenüber dem dazwischen liegenden Zeitalter der Territorial- und später der Volkswirtschaften, in dem für einen .international' tätigen Außenhandelsverbund von relativ autonomen Städten kein Platz mehr war.

\section{Hanse und Europäische Union}

Wenden wir uns abschließend den strukturellen Ähnlichkeiten zu, die die Hanse und die Europäische Union miteinander haben, wobei die Einung, wie der Zusammenschluss rechtlich gleichgestellter Partner im Mittelalter genannt wurde, von zentraler Bedeutung ist. Innerwissenschaftlich, also im Diskurs der Historiker, spielt die Wiederbeschäftigung mit der Einung als einer grundlegenden Organisationsform des Mittelalters eine große Rolle. Dieses der aristokratisch-herrschaftlichen Adelsgesellschaft gegenüberstehende Organisationsprinzip der mittelalterlichen Gesellschaft fand und findet naheliegenderweise in der demokratischen Gesellschaft der BRD mehr lebensweltliches Interesse ${ }^{118}$ als z. B. in der obrigkeitlich strukturierten deutschen Gesellschaft des wilhelminischen Kaiserreichs und des Dritten Reiches.

Ähnlich wie seit der zweiten Hälfte des 14. Jahrhunderts die Städte in der Hanse bemühen sich in der Europäischen Union rechtlich gleichgestellte Staaten um einen Konsens im Hinblick entweder auf weitergehende Integration oder auf Beibehaltung der erreichten Wirtschaftsgemeinschaft. Unser Interesse gilt zunächst der Entscheidungsfindung.

\section{Entscheidungsfindung in der Hanse}

Die Hanse war ein Zusammenschluss von rechtlich gleichgestellten Mitgliedern ohne hierarchische Spitze. Die oberste gemeinschaftliche Institution der Hanse, die hansische Tagfahrt (der Hansetag), hatte keine den einzelnen Mitgliedern übergeordnete Kompetenz. Somit gab es keine herrschaftliche Zwangsgewalt, auch keinen gemeinsamen Eid, der eine gemeinsame Politik garantieren konnte.

Alle Beschlüsse mussten daher einstimmig gefasst werden und darüber hinaus, um rechtswirksam zu werden, in einzelstädtisches Recht und in das Recht des gemeinen Kaufmanns in den Auslandsniederlassungen, den Kontoren, umgesetzt werden.

In den einzelnen Hansestädten gab es drei unterschiedliche Ebenen der Beschlussfassung. Welche davon jeweils angewendet wurde, war von der

\footnotetext{
${ }^{118}$ Siehe dazu oben bei Anm. 46.
} 
Art bzw. der Tragweite des behandelten Problems abhängig. ${ }^{119}$ Die untere, erste Ebene bildeten gewöhnliche, den Bürgermeistern zur Erledigung aufgetragene Geschäfte, die zweite Geschäfte von einigem Gewicht (negotia ponderis alicuius), die von den Bürgermeistern zusammen mit dem Rat beschlossen werden mussten, und schließlich als drittc Ebcne beschwerliche und große Geschäfte (negotia ardua et magna), zu deren Erledigung Bürgermeister und Ratsherren ausdrücklich den Rat und die Zustimmung der Meister der Handwerksämter und der (nicht in Handwerksämter gegliederten) übrigen Gemeinde herbeiführen mussten. ${ }^{120}$

Diese verfassungsrechtliche Grundlage war für die Beschlussfassung der Hanse und für die Durchführung dieser Beschlüsse von zweifacher Bedeutung. Zum ersten - für die Beschlussfassung - im Hinblick auf die Kompetenzen der Ratssendeboten, die zu einem Hansetag geschickt wurden. Diese Kompetenzen mussten von Rat oder Rat und Gemeinde der Mitgliedsstadt speziell für jeden Einzelfall auf die Ratssendeboten übertragen werden, weswegen die genaue Nennung der Tagesordnungspunkte in den Einladungsschreiben zu den Hansetagen von enormer Wichtigkeit war: ${ }^{121}$ Die Ratssendeboten konnten anschließend auf der Tagfahrt nur im Rahmen dieser übertragenen Kompetenzen Beschlüsse der Versammlung mit herbeiführen. Am Ende des Hansetages fanden, wie wir oben schon

${ }^{119}$ Die von PITZ, Bürgereinung (wie Anm. 42), im zweiten Kapitel (S. 65-245) herangezogenen Beispiele aus 14 wendischen und niedersächsischen Städten sowie aus Köln, Nordhausen und Danzig reichen von 1340 bis 1458. Nach meiner Kenntnis sind die Art und die Rechtsgrundlagen der Beschlussfassung der Hansetage im 16. und 17. Jh. die gleichen geblieben.

${ }^{120}$ Urkundenbuch der Stadt Lübeck (im Folgenden: UBStl) Bd. 2, Lübeck 1858. Nr. 715 , S. 664: s. dazu PITZ. Verfassungsgeschichtliche Forschungen, in: Eckhard MULLER-MERTENS, Heidelore BÖCKER (Hg.), Konzeptionelle Ansätze der Hanse-Historiographie (Hansische Studien XIV), Trier 2003, S. 141-154, hier S. 144-147; DERS.. Bürgereinung (wie Anm. 42), S. 65-76; zur Kasuistik der hochbeschwerlichen Geschäfte ebd. S. 229f. Zu den unterschiedlichen Formen dieser ,.konsensgestützten Herrschaft“ (dieser Begriff nach Ulrich MEIER und Klaus SCHREINER, ,Regimen civitatis“. Zum Spannungsverhältnis von Freiheit und Ordnung in alteuropäischen Stadtgesellschaften, in: Stadtregiment und Bürgerfreiheit. Handlungsspielräume in deutschen und italienischen Städten des späten Mittelalters und der frühen Neuzeit (Bürgertum. Beiträge zur europäischen Gesellschaftsgeschichte, Bd. 7), Göttingen 1994, S. I1-34, S. 15f.), s. Bernd KANNOWSK1. Bürgerkämpfe und Friedebriefe. Rechtliche Streitbeilegung in spätmittelalterlichen Städten (Forschungen zur deutschen Rechtsgeschichte: Bd. 19). Köln u. a. 2001, S. 170f; Eherhard ISENMANN, Die deutsche Stadt im Spätmittelalter 1250-1500. Stadtgestalt, Recht. Stadtregiment. Kirche, Gesellschaft. Wirtschaft. Stuttgart 1998, S. 132, verwendet den Begriff nicht und beurteilt die bürgerliche Mitwirkung anders; zu den Städten lübischen Rechts s. Wilhelm EBEL, Lübisches Recht. Erster (und einzig erschienener Band). Lübeck 1971, S. 288, 294-296.

${ }^{121}$ Zu den Ladungsschreiben s. PITZ, Bürgereinung (wie Anm. 42), S. $379 \mathrm{ff}$.; DERS., Einstimmigkeit oder Mehrheitsbeschluss? Ein heimlicher Verfassungsstreit um die Vollmachten der Ratssendeboten auf den Hansetagen, in: Verwaltung und Politik in den Städten Mitteleuropas. Beiträge zu Verfassungsnorm und Verfassungswirklichkeit in altständischer Zeit, hg. von Wilfried EHBRECHT. Köln u. a. 1994, S. 115-146, hier 122f., 126. 
sahen, nur einstimmig gefasste Beschlüsse Aufnahme in den zu verabschiedenden Rezess.

Um Rechtskraft zu erlangen mussten - und das ist der zweite Punkt von Bedeutung - dessen Bestimmungen in den Kontoren und in den Städten publiziert und dadurch in das Recht des gemeinen Kaufmanns und in Stadtrecht umgesetzt werden. ${ }^{122}$ Offensichtlich galten Hansetagsbeschlüsse in der Regel als Geschäfte der o. g. zweiten Ebene, da sie in Burspraken oder durch Aushang auf dem Rathaus verkündet wurden. ${ }^{123}$ Bei militärischen Bündnissen, wie den eigentlich außerhalb der Hanse stehenden tohopesaten, die zu den negotia ardua et magna zählten, war dagegen die Zustimmung der Gemeinde unerlässlich. ${ }^{24}$

Bis ins letzte ist die Frage der Verbindlichkeit der in den Rezessen der Hansetage festgehaltenen Beschlüsse allerdings noch nicht beantwortet. Es gibt durchaus kontroverse Standpunkte in der hansischen Geschichtsforschung, vor allem im Hinblick auf die Folgepflicht für diejenigen. die sich der abzeichnenden Mehrheitsmeinung anschließen mussten bzw. für die Hansestädte, die an dem betreffenden Hansetag nicht teilgenommen hatten (oftmals ja aufgrund des Verdachts, dass dort Beschlüsse gefasst werden könnten, die nicht in ihrem Interesse lägen). ${ }^{125}$

Wie es auch im einzelnen gewesen sein mag, eines liegt klar zutage: Das grundsätzliche und auf der Basis des Einungsrechts, nach dem alle Mitglieder gleichberechtigt waren, nicht veränderbare Prinzip der Einstimmigkeit hatte zur Folge, dass die Herbeiführung von Konsens über Jahrhunderte das zentrale Anliegen jeder allgemein-hansischen Politik war. Diese Aufgabe musste eine der Hansestädte übernehmen. Diese Stadt war Lübeck. Neben der Geschäftsführung der hansischen Angelegenheiten in den Zeiträumen zwischen den Hansetagen, die dem Rat von Lübeck gemeinsam mit den Räten der wendischen Hansestädte 1418 schriftlich übertragen wurde, neben den u. a. daraus folgenden diplomatischen Aktivitä-

\footnotetext{
${ }^{122}$ Laut PITZ, Bürgereinung (wie Anm. 42), S. 408-415, $215 \mathrm{ff} ., 220 \mathrm{ff} ., 226 \mathrm{ff}$. waren die Rezesse vor der Verkündung als städtisches Recht nur leges imperfectae; ebd., S. 333-335 zum Vorrang der beschworenen Bürgerpflichten vor der Verpflichtung durch Hanserezess, S. 353f. zu Konflikten zwischen Stadtrecht und Kaufmanns- oder Hanserecht; DERS., Verfassungsgeschichtliche Forschungen (wie Anm. 120), S. 152f.

${ }^{123}$ PITZ, Bürgereinung (wie Anm. 42), S. 408-415.

${ }^{124}$ PITZ. Bürgereinung (wie Anm. 42), S. 415-417.

${ }^{125}$ Nach LANDWEHR, Seerecht (wie Anm. 115), S. 30 Anm. 83, waren die Rezesse für die Städte selbst und ihre Räte bereits durch die Verwillkürung auf dem Hansetag verbindlich. Daraus ergäbe sich allerdings die eigenartige Situation, dass Rechtssetzungen für Städte selbst und ihre Räte verbindlich gewesen sein könnten, für die Bürger der jeweiligen Städte jedoch nicht, nämlich dann nicht, wenn sie nicht verkündet worden waren. Sehr lesenswert sind die zusammenfassenden „Bemerkungen zur Rechtsnatur der hansischen Normen“ in Landwehrs ,Seerecht', S. 27-33.
} 
ten, die der Rat der Stadt über Jahrhunderte in hansischen Angelegenheiten zeigte, hatte ein Bürgermeister der Travestadt den Vorsitz auf den meisten Hansetagen (weil die meisten in Lübeck stattfanden), auf denen ein Konsens zwischen den widerstreitenden Interessen der einzelnen Städtegruppen gefunden werden musste.

\section{Entscheidungsfindung in der Europäischen Union}

Auch die Europäische Union ${ }^{126}$ ist ein Zusammenschluss von rechtlich gleichgestellten Mitgliedern, in mittelalterlicher Terminologie folglich eine Einung (wenn auch in institutioneller und organisatorischer Hinsicht viel differenzierter als die Hanse). Man bezeichnet die europäische Organisation als eine Dachorganisation, die auf drei Säulen ruht, die 1993 durch den Vertrag von Maastricht eingeführt wurden. Die erste Säule sind die Europäischen Gemeinschaften (EG), die zweite Säule die gemeinsame Außen- und Sicherheitspolitik (GASP), die dritte Säule die polizeiliche und justizielle Zusammenarbeit in Strafsachen (PJZS).

In Bezug auf die Beschlussfassung sind in den Europäischen Gemeinschaften (EG, erste Säule) qualifizierte Mehrheitsentscheidungen inzwischen der Normalfall. Einstimmigkeit ist allerdings bei konstitutionellen Fragen, die einer Vertragsänderung gleichkommen, erforderlich und bei Fragen, die von den Mitgliedsstaaten als besonders sensibel empfunden werden. In der zweiten und dritten Säule ist nach wie vor Einstimmigkeit die Regel.

Die tragende Säule der EU ist diejenige der Europäischen Gemeinschaften, die aus der ehemaligen Europäischen Wirtschaftsgemeinschaft, nunmehr Europäische Gemeinschaft genannt, und aus der Europäischen Atomgemeinschaft (Euratom) besteht. ${ }^{127}$ Nur in diesen von den Gemeinschaftsverträgen erfassten Politikbereichen haben die Mitgliedsstaaten einen Teil ihrer Kompetenzen an die Gemeinschaft(en) abgegeben, nur hier gilt die supranationale Form der Entscheidungsfindung (Agrar-, Fischerei-, Handels- und Verkehrspolitik, Binnenmarkt, Währungspolitik). Entscheidungen können hier in bestimmten Fällen auch gegen den Willen eines oder mehrerer Mitgliedsstaaten getroffen werden. Es gibt eine Vielzahl von Entscheidungswegen, die davon abhängen, um welche Materie es

\footnotetext{
${ }^{126}$ Das Folgende nach Dietmar HERZ. Die Europäische Union. München 2002; Wolf D. GRUNER. Wichard WOYKE, Europa-Lexikon. Länder, Politik, Institutionen (becksche reihe 1506), München 2004; Werner WEIDENFELD (Hg.), Europa-Handbuch (Bundeszentrale für politische Bildung, Schriftenreihe Bd. 373). Bonn 2002.

${ }^{127}$ Die Europäische Gemeinschaft für Kohle und Stahl (EGKS) erlosch am 22. Juli 2002, als der EGKS-Vertrag auslief; HeRZ, Europäische Union (wie Anm. 126), S. 66.
} 
sich handelt, wer daran beteiligt ist und wie abgestimmt wird (Mitentscheidungsverfahren, Zustimmungsverfahren, Zusammenarbeitsverfahren, Anhörungsverfahren, einfaches Verfahren). Auf diesen Wegen erlassen Rat und Kommission ,Verordnungen", ,Richtlinien" und ,Entscheidungen ", sprechen ,Empfehlungen' aus oder geben ,Stellungnahmen' ab. ${ }^{128}$

In den Geschäftsbereichen der beiden anderen „Säulen“ werden Entscheidungen dagegen nach dem klassischen intergouvernementellen Muster der internationalen Politik getroffen, als Verhandlungsprozesse zwischen Staaten. In diesen Bereichen bedürfen die Beschlüsse der Einstimmigkeit, also eines Konsenses aller Staaten. Die supranationalen Organe - Kommission, Parlament und Gerichtshof - haben hier nur stark eingeschränkte Befugnisse. Die Kernkompetenzen des souveränen Staates, die Innen-, Justiz- und die Außenpolitik sind folglich nach wie vor in der Hand der Einzelstaaten und spiegeln damit die Vorsicht der Mitgliedstaaten gegenüber weitgehenden Integrationsschritten. Durch das Einstimmigkeitserfordernis ist bei diesen beiden „Säulen“ ausgeschlossen, dass sich ein Politikbereich völlig konträr zu den Vorstellungen eines oder mehrerer Mitgliedsstaaten entwickelt. ${ }^{129}$

\section{Strukturelle Ähnlichkeiten zwischen Hanse und EU}

Auf der obersten Ebene des Vergleichs lässt sich feststellen, dass beide Institutionen keine Rechtspersönlichkeiten waren und sind. „Die europäische Union ist ein heterogenes Gebilde, das über keine Rechtspersönlichkeit verfügt wie die Einzelgemeinschaften“. ${ }^{130}$ Die Hanse wiederum ,lässt sich mit modernen staatsrechtlichen Begriffen nicht erfassen; selbst die Zeitgenossen haben sich im 16. Jh. zeitweise außerstande gesehen, die Hanse als verhandlungsfähiges corpus politicum anzuerkennen". ${ }^{131}$ Rechtspersönlichkeiten waren die einzelnen Hansestädte und die Kontore, aber nicht die Hanse als Gesamtorganisation. ${ }^{132}$ Erst gegen Ende ihrer

\footnotetext{
128 „Eine Verordnung hat allgemeine Geltung, ist in allen ihren Teilen verbindlich und gilt unmittelbar in jedem Mitgliedsstaat. Die Richtlinie ist [...] hinsichtlich des zu erreichenden Ziels verbindlich, überlässt jedoch den innerstaatlichen Stellen die Wahl der Form und Mittel. Mit einer Richtlinie wird [...] in einem ersten Schritt eine Rahmenregelung erlassen [...]. Die Entscheidung ist in allen Teilen für diejenigen verbindlich. die sie bezeichnet. [...] Empfehlungen und Stellungnahmen sind nicht verbindlich"; Wichard WOYKE, Europa: Wirtschaft und Recht, in: Europa-Lexikon (wie Anm. 126), S. 65-70, hier S. 69.

${ }^{129}$ Das ganze nach HERZ. Europäische Union, S. 66-69.

${ }^{130}$ WOYKE, Europa: Wirtschaft und Recht (wie Anm. 128), S. 66.

${ }^{131}$ Volker HenN, Was war die Hanse?, in: Die Hanse - Wirklichkeit und Mythos, hg. von Jörgen BRACKER, Bd. 1. Hamburg 1989. S. 15-21, hier S. 20.

${ }^{132}$ Die rechtsgelehrten Diskussionen über die Rechtsnatur der Hanse in der Frühen Neuzeit behandeln Albrecht CORDES, Die Rechtsnatur der Hanse. Politische, juristische und histori-
} 
Geschichte, als sie ihre wirtschaftliche und politische Bedeutung bereits eingebüßt hatte, erreichte die Hanse 1648 auf dem Osnabrücker Friedenskongress die „paradoxe Stellung eines völkerrechtlich anerkannten staatsartigen Subjekts ohne eigenes Territorium" “. ${ }^{133}$ Beide Organisationen agierten und agieren folglich im wirtschafts- und machtpolitischen System ihrer jeweiligen Gegenwart ohne über eine eigene Rechtspersönlichkeit zu verfügen.

Weiterhin sind sowohl die Hanse als auch die EU in ihren beiden „Säulen" gemeinsame Außen- und Sicherheitspolitik" (GASP) und ,polizeiliche und justizielle Zusammenarbeit in Strafsachen ' (PJZS) in ihren Gremien über das Einstimmigkeitserfordernis nicht hinausgekommen. Im Vergleich zur EU mit ihren 27 souveränen Mitgliedern hatte die Hanse ca. 70 Städte, die aktiv an der hansischen Politik teilnahmen und die alle außerdem unter der Herrschaft eines adligen Stadtherrn standen, auf dessen Interessen sie - mehr oder weniger - Rücksicht nehmen mussten. Nur wenige konnten sich weitgehende Autonomie erkämpfen. Man mag sich streiten, unter welchen der beiden Voraussetzungen man leichter zu Kompromissen gelangen konnte; einfacher als heute war es zu Zeiten der Hanse angesichts der großen Zahl beteiligter und zu berücksichtigender Personen bzw. Institutionen sicherlich nicht.

Beide Institutionen nahmen bzw. nehmen mit ihren Beschlüssen Einfluss auf die einzelnen Mitglieder und beeinfluss(t)en deren Rechts- und Wirtschaftsleben in weit stärkerem Maße als zwischenstaatliche Organisationsformen - wie z. B. die UN - es vermochten und vermögen. Dabei tritt jedoch ein deutlicher Unterschied zwischen Hanse und EU zu Tage. Die EU kann innerhalb der ersten „Säule“, den Europäischen Gemeinschaften (EG), im Rahmen der unterschiedlichen Verfahren EU-Recht für die Mitgliedstaaten verbindlich (bei Strafe) beschließen. Die Beschlüsse der hansischen Tagfahrten mussten dagegen von den einzelnen Städten in Stadtrecht umgesetzt werden, um rechtsverbindlich $\mathrm{zu}$ werden (wie es heute in der EU für die beiden „Säulen“ GASP und PJZS - modifiziert auf den Nationalstaat - auch der Fall ist). Wie die Hanse prägen die EG (erste „Säule“) der EU die Rechtsordnung ihrer Mitgliedsstaaten in weiten Bereichen entscheidend mit, aber anders als jene können sie dieses Recht mittels Verfahren umsetzen, die es in vielen Fällen ermöglichen, einzelne Staaten zu überstimmen. ${ }^{134}$

sche Diskurse, in: HGbll. 119, 2001, S. 49-62; Wilhelm EBEL. Die Hanse in der deutschen Staatsrechtsliteratur des 17. und 18. Jahrhunderts, in: HGbll. 65/66, 1940/41, S. 145-169.

${ }^{133}$ CORDES, Rechtsnatur (wie Anm. 132), S. 62.

${ }^{134}$ HERZ, Europäische Union (wie Anm. 126), S. 110; s. o. bei Anm. 126 und 127. 
Im Unterschied zu einem ,klassischen' Staat fehlt der EU das neben Staatsvolk und Staatsgebiet dritte Kriterium von Staatlichkeit: die Staatsgewalt, also die Möglichkeit „erfolgreich das Monopol legitimen physischen Zwanges für die Durchführung der Ordnungen in Anspruch" zu nehmen (Max Weber). Der europäischen Union fehlt (wie der Hanse) die Zwangsgewalt. Zur Durchsetzung ihrer Rechtsordnung bedient sie sich der Exekutive ihrer Mitgliedsstaaten (wie auch die Hanse sich der Exekutive ihrer Mitgliedsstädte bediente); die Europäische Union hat keine eigene Polizei - sieht man einmal von Europol (Europäisches Polizeiamt) ab, das aber bislang keine operativen Befugnisse hat -, und sie hat kein eigenes Militär. Auch hier sind die Parallelen zur Hanse schlagend. Wenngleich die Unionsorgane durchaus über Sanktionsmöglichkeiten verfügen (z. B. Zwangsgelder, die der Europäische Gerichtshof verhängen kann), „letztlich fehlt ihr das Schwert des Leviathan“. 135

Eine weitere Ähnlichkeit zeigt sich am Beispiel des - im Falle der Hanse nur beabsichtigten - Weges vom wirtschaftlichen zum politischen Verband. Beide Organisationen waren zu Anfang rein wirtschaftlich ausgerichtet. Die Hanse entstand gewissermaßen in den Auslandsniederlassungen, in denen die niederdeutschen Kaufleute - und das war ihre bedeutendste Innovation - ihre interne Konkurrenz beilegten und nach außen geschlossen auftraten. Von dort „wuchs" diese gemeinsame Interessenvertretung in die städtischen Räte hinein und wurde aufgrund der dominierenden Rolle der Fernkaufleute in den Seestädten und aufgrund ihres großen Einflusses in den Binnenstädten zu einer zentralen Größe der Politik der Gesamtstadt (was die anderen, nicht am Fernhandel beteiligten Bürger davon hielten, darauf kommen wir weiter unten zu sprechen). Die so entstandene Hanse war durch die gemeinsame Nutzung, Verteidigung und wenn möglich - Ausweitung der im Ausland erworbenen Privilegien definiert. Als in der zweiten Hälfte des 14. Jahrhunderts unter den Anforderungen der politischen und der wirtschaftlichen Krise deutlich wurde, dass die Art der Beschlussfassung der Hansestädte den Anforderungen besonders in Kriegszeiten nicht gerecht wurde, versuchte Lübeck gemeinsam mit den wendischen Städten der Hanse eine schlagkräftige politische Führung zu geben. ${ }^{136}$ Das Ziel wurde zwar nicht erreicht - nicht zuletzt wegen des von Köln und von den westfälischen Städten gegen diese Politisierung geleisteten Widerstandes -, aber die lübeckisch-wendischen Bemühungen führten doch zur Existenz von zwei „Hansen“: der rein handelswirtschaftlich ausgerichteten „Privilegienhanse“ und einer ,politi-

\footnotetext{
${ }^{135}$ HERZ, Europäische Union (wie Anm. 126), S. 111.

${ }^{136}$ PITZ, Bürgereinung (wie Anm. 42), S. $366 \mathrm{f}$.
} 
schen Hanse“, in der Lübeck von vielen Städten, die das Recht oder die Pflicht bejahten, die von Lübeck ausgeschriebenen Tagfahrten zu besuchen, als Haupt der Hanse anerkannt wurde. ${ }^{137}$ Dieser Schwebezustand zwischen zwei unterschiedlichen Verfassungsformen erinnert an den heutigen Zustand der EU, die, aus EWG, EGKS und Euratom entstanden, sich die politische Einigung ihrer Mitgliedsstaaten zum Ziel gesetzt hat, aber auch gespalten ist in eine Gruppe von Mitgliedern, die einen Wirtschaftsverbund befürworten und anderen, die das Ziel der politischen Vereinigung verfolgen.

Abschließend sei noch auf eine weitere Übereinstimmung hingewiesen, die jedoch nicht die beiden Organisationen selbst, sondern deren Akzeptanz durch die Bevölkerung der von ihnen erfassten Gemeinwesen betrifft. Die Masse der Bevölkerung steht derzeit der EU ähnlich indifferent gegenüber wie anscheinend die Masse der Bürger und Einwohner der Hansestädte der Hanse gegenüberstanden. Sie erleben das Vereinte Europa als ein wirtschaftliches und regulatorisches Vorhaben, das ihnen bislang so fremd blieb wie den nicht direkt am Fernhandel beteiligten städtischen Bevölkerungsgruppen die Verzahnung der individuellen Fernhandelsinteressen vieler Ratsherren mit dem gesamtstädtischen Wohl besonders in Krisenzeiten suspekt war. In beiden Fällen kann man von einem permissiven Konsens sprechen, von der stillschweigenden Unterstützung oder zumindest Duldung der Eliten durch ihre Gesellschaften, solange das jeweilige politische System als vorteilhaft für die Gesellschaft wahrgenommen wird. ${ }^{138}$ Beide Organisationen wurden und werden weitgehend als Organisationen von Eliten erlebt, die jeweilige Bevölkerung empfand und empfindet die in ihnen getroffenen Entscheidungen nicht als dem Wohl der Gesamtgesellschaft dienend.

In Bezug auf die Hanse mag ein Beispiel aus dem Anfang des 15. Jahrhunderts genügen: Die aus Kaufleuten und Handwerkern bestehende Opposition, die sich 1406 gegen den Lübecker Rat in der Travestadt formiert hatte, begründete ihr Vorgehen u. a. damit, dass der Rat zu wenig das Wohl der Stadt im Auge gehabt, sondern deren Mittel für die Hanse vergeudet hätte. ${ }^{139}$ Das ist kein Zufallszeugnis, da aus anderen Städten

\footnotetext{
${ }^{137}$ Hammel-Kiesow, Hanse (wie Anm. 17), S. 79-83, nach PITz, Bürgereinung (wie Anm. 42), S. 343-365.

${ }^{138}$ Wichard WOYKE, Europa: Politik und Gesellschaft, in: Europa-Lexikon (wie Anm. 126), S. 60-65, hier S. 61.

${ }^{139}$ Die Chroniken der deutschen Städte vom 14. bis ins 16. Jahrhundert Bd. 26, Lübeck Bd. 2. hg. von Karl KoppmanN. Reprint der Ausgabe Leipzig 1899. Göttingen 1967, S. 405, Abs. 5 und 7; s. dazu auch Carl WeHRMANN, Der Aufstand in Lübeck bis zur Rückkehr des alten Raths, in: HGbll. Bd. 3 [Teil 2], Jg. 8, 1878, S. 103-156, hier 106; für diesen Hinweis danke ich Herrn Volker Henn.
} 
ähnliche Argumentationsmuster vorliegen, wenn auch ohne explizite Nennung der Hanse. Dort werden die kaufmännischen. die fernhändlerischen Führungsgruppen als Gegner der städtischen Opposition genannt, was im Prinzip das gleiche war. Diese Zeugnisse bekommen erst richtig Gewicht, wenn wir uns anschauen, wer überhaupt in Außen- und Innensicht ein ,Hanse, war.

Thomas Behrmann hat das ,hansische“ Selbstverständnis der niederdeutschen Kaufleute und Städte untersucht und fand bis weit in das 15. Jahrhundert hinein weder bei Kaufleuten noch bei Städten ,überzeugende Belege für ein ,ausgeprägtes hansisches " Selbstverständnis"; erst in der zweiten Hälfte des 16. Jahrhunderts konnte er schwache Hinweise dafür finden. Stattdessen lassen ,wirtschaftliche, rechtliche oder politische Gründe - in der Repräsentation nach außen oder zur Herstellung eines Wir-Gefühls nach Innen“ - eine hansische Terminologie erklären. Der Begriff ,Hanse' beschränkte sich meist auf die diplomatische Ebene, die Kaufleute selbst wurden in der Regel schlicht mercatores Alemannie oder Esterlinge genannt, sie selbst bezeichneten sich so gut wie nie als Kaufleute der deutschen oder sonst einer Hanse. ${ }^{140}$

Hingewiesen sei schließlich bezüglich der ,Eliten" noch auf den Erklärungsansatz von Friedrich Bernward Fahlbusch, der den Erfolg der Städte und des hansischen Verbandes ,auf das Wirken einer informellen Führungsgruppe [zurückführt], die dreifach homogen war: in ihrer politischsozialen Position, in ihren wirtschaftlichen Interessen und in ihrer elitären Identität. Diese Gruppe nutzte subsidiär und sekundär die den Zeiten entsprechenden Rechtsmaterien und Organisationsformen und ermöglichte somit Existenz und Funktionieren des Verbandes". Fahlbusch bezeichnet diese Gruppe mit dem Begriff „Amigonat“, „um alle sich überlagernden, gegenseitig beeinflussenden Arten von in Verwandtschaft, Freundschaft, Geschäftspartnerschaft und politisch-sozialen Ämtern begründeten Beziehungen, um die diffuse Vermischung öffentlich-offizieller Amtsinhabe, informeller Machthabe und persönlicher Interessen zu erfassen". Erst dieses „amigonöse Gemenge“ habe das Funktionieren der unverfassten Ordnung des Verbandes ermöglicht. ${ }^{141}$

Die Hanse und die Europäische Union waren bzw. sind sich somit nicht nur auf der rechtlichen Ebene strukturell ähnlich, da beide weder eine

\footnotetext{
140 Thomas BEHRManN, ,Hansekaufmann“, ,Hansestadt , ,Deutsche Hanse'? Über hansische Terminologie und hansisches Selbstverständnis im späten Mittelalter, in: Thomas SCHARFF und Thomas BEHRMANN (Hg.): Bene vivere in communitate. Beiträge zum italienischen und deutschen Mittelalter. Hagen Keller zum 60. Geburtstag überreicht von seinen Schülerinnen und Schülern. Münster u. a. 1997, S. 155-176, hier S. 169 (Zitat) und 161.

${ }^{141}$ FAHLBUSCH. Führungsgruppe (wie Anm. 117), S. 59.
} 
internationale Organisation ${ }^{142}$ noch ein Staat sind bzw. waren. Beide sind / waren ein Gebilde sui generis, ein Konstrukt eigener Art, das weder Vorbilder noch Parallelen hat(te). Beide haben und hatten zusätzlich auch erhebliche Probleme hinsichtlich der Akzeptanz seitens der gesellschaftlichen Gruppen, die nicht unmittelbar in die Aktivitäten der Organisationen eingebunden waren und sind.

Dennoch hat die Hanse auf den genannten Grundlagen über rund 500 Jahre, ein halbes Jahrtausend lang, die Fernhandelsinteressen ihrer Kaufleute vertreten und die Sicherung der autonomen - zumindest - Außenhandelspolitik ihrer Mitgliedstädte verfolgt. Ihre Mittel waren Diplomatie, wirtschaftliche Zwangsmaßnahmen wie Handelsblockaden und - wenn es anders nicht mehr ging - der Einsatz militärischer Macht.

Der große Unterschied zu den Werten der die damalige Zeit prägenden Adelsgesellschaft wird an den Motiven der Kriegführung besonders deutlich. Während der Adel der verletzten Ehre wegen jahre- und jahrzehntelange Fehden und Kriege führte, schluckten die hansischen Diplomaten manche Beleidigung, zahlten sogar Entschädigungen für nicht begangene Taten, nur um den Handel nicht zu gefährden. ${ }^{143}$ Wenn es aber an dessen Substanz ging, zeigten sie (vereinzelt) bis ins 17. Jahrhundert hinein, dass sie in der Lage waren, es mit den Flotten und Heeren der nordischen Königreiche und der Territorialfürsten des Reiches aufzunehmen und ihre einmal errungenen Handelsvorrechte und ihre Autonomie - zumindest im Falle Braunschweigs - zu verteidigen.

\section{Zusammenfassung und Fazit}

Versuchen wir ein Fazit. Welche Bezüge lassen sich zwischen der Hanse und Europa bzw. EU und zwischen Hanse und Globalisierung erkennen?

Im Hinblick auf die Charakterisierungen der Hanse als „,europäische“ Organisation, konnte klar gestellt werden (II), dass sie eine niederdeutsche Organisation war, deren Kaufleute allerdings europaweit, nämlich im Gebiet von 25 heutigen europäischen Staaten, tätig waren.

\footnotetext{
${ }^{142}$ Die Kompetenzen, Verfahrensweisen und Handlungsbefugnisse, die der Union und ihren Organen in den völkerrechtlichen Verträgen zwischen den Mitgliedsstaaten, die ihre rechtliche Grundlage bilden, zugestanden wurden. gehen über das Muster einer „klassischen“ internationalen Organisation weit hinaus; HERZ, Europäische Union (wie Anm. 126). S. 110.

${ }^{14.3}$ Dieser Gesichtspunkt war offensichtlich ein so wesentlicher Bestandteil des Selbstverständnisses der Führungsschichten in Lübeck, dass er sich in einem Stadtlobgedicht des Erasmus Sarcerius auf Lübeck aus dem Jahr 1537 findet; Rolf HAMMEL-KIESOW, Hansestädte im Städtelob der frühen Neuzeit. In: Das Bild und die Wahrnehmung der Stadt und der städtischen Gesellschaft im Hanseraum im Mittelalter und in der frühen Neuzeit, hg. von Roman CZAJA. Toruń 2004, S. 19-55, hier S. 30.
} 
In Abschnitt III wurden die Auswirkungen des hansischen Handels insbesondere bezogen auf die Ausgangs- und Zielländer dargestellt: Demnach sorgte die Hanse für einen relativ freien Warenverkehr im nördlichen Europa, gewissermaßen für einen Vorläufer eines gemeinsamen Marktes. ${ }^{144}$ Die regionale Begrenzung von Waren und Produkten wurde aufgehoben und für deren massenhafte und weiträumige Verbreitung gesorgt. Dabei wurden insbesondere die Länder des nordöstlichen Europa in die mittel- und westeuropäische Wirtschaft integriert, indem die hansischen Kaufleute diese Märkte für die Exportprodukte des Nordostens erschlossen. Über die Nachfrage nach diesen oft aufbereiteten Produkten, regten die hansischen Kaufleute in den Erzeugerländern die Produktion und dadurch möglicherweise die Bildung, jedenfalls aber den stärkeren Ausbau einer gewerblichen Infrastruktur an.

In diesem Rahmen war die Hanse in ein europaweites Zulieferungssystem für die hoch entwickelte Tuchherstellungsregion Flandern eingebunden. Sie war Teil einer diversifizierten Wirtschaft, die in Bezug auf die zur Produktion bestimmter Güter notwendigen Materialien bereits eine standortunabhängige Wirtschaftsweise ermöglichte. In der Herstellungsregion saß ,nur" noch das Herstellungs-know-how. Das war, wenn man unter Globalisierung die Intensivierung und Beschleunigung grenzüberschreitender Transaktionen bei deren gleichzeitiger räumlicher Ausdehnung versteht, Globalisierung bzw. ,Europäisierung' im Mittelalter (IV). Strukturelle Ähnlichkeiten begegnen weiter auf dem Gebiet des effektiven Informationsaustausches, der Transportmittel und den Ansätzen zur Standardisierung von Maßen und Währungen, von rechtlichen Institutionen, überhaupt zur Schaffung von stabilen Rahmenbedingungen.

Im organisatorischen Aufbau der Hanse war dieser im Handelsbereich starke europäische Aspekt nach allem, was wir bislang wissen, nicht sehr ausgeprägt (III). Handelsgesellschaften mit nicht hansischen Kaufleuten bildeten die Ausnahme (hier dürfte jedoch, wie wir sahen, eine Forschungslücke vorliegen). Es gab aber Beispiele enger Zusammenarbeit im Handel mit Gotländern im 13. und mit den Londoner mercers im 15. Jahrhundert und bei der Warenproduktion in Flandern kann man im 15. und im beginnenden 16. Jahrhundert enge wirtschaftliche Verbindungen zu den Tuchproduzenten beobachten, die bis zu Abnahmegarantien kompletter Jahresproduktionen gingen.

Ihren eigenen Raum schotteten die Hansen ab, indem sie fremde Kaufleute zu ihren Netzwerken seit dem späten 13. und 14. Jahrhundert nur

\footnotetext{
${ }^{144}$ Gemeinsamer Markt insofern, als die Hanse und die hansischen Kaufleute, wie gesagt, einen relativ freien Warenverkehr ermöglichten. Von einer Verschmelzung der regionalen Märkte zu einem einheitlichen Binnenmarkt konnte selbstverständlich keine Rede sein.
} 
dann zuließen, wenn sie das Bürgerrecht einer Hansestadt annahmen (also keine ,Fremden' mehr waren). Das war jedoch keine prinzipielle Fremdenfeindlichkeit, sondern beruhte darauf, dass ein rechtlicher Zugriff bei Verstößen nur über das jeweilige Stadtrecht erfolgen konnte, in das hansische Beschlüsse (außerhalb der Kontore) immer umgesetzt werden mussten. Außerdem verschärften sich seit dem späten 14. Jahrhundert die Probleme mit den Privilegiengebern, wenn die Waren hansischer Kaufleute von nichthansischen Waren - und das heißt eben auch von denjenigen nichthansischer Mitglieder in einer Handelsgesellschaft - nicht unterschieden werden konnten.

Abschnitt IV behandelte schließlich die bereits angesprochenen strukturellen Ähnlichkeiten zwischen dem Zeitalter der Hanse und der Globalisierung sowie diejenigen zwischen der Hanse und der Europäischen Union, wobei der Zusammenschluss rechtlich gleichgestellter Partner ohne hierarchische Spitze bei beiden Organisationen die Grundlage war und ist, auf der spezifische Wege der Entscheidungsfindung, vor allem der Herbeiführung von Konsens (Erfordernis der Einstimmigkeit) entwickelt wurden und werden. Weitere strukturelle Ähnlichkeiten: Beide Organisationen agierten und agieren im wirtschafts- und machtpolitischen System ihrer jeweiligen Gegenwart ohne über eine eigene Rechtspersönlichkeit zu verfügen, beide nahmen bzw. nehmen mit ihren Beschlüssen Einfluss auf die einzelnen Mitglieder und beeinfluss(t)en deren Rechts- und Wirtschaftsleben in weit stärkerem Maße als zwischenstaatliche Organisationsformen es vermochten und vermögen, beide suchten und suchen den Weg von einem rein wirtschaftlichen zu einem politischen Verband und beiden Organisationen stand und steht die Masse der von ihren Entscheidungen betroffenen Bürger und Einwohner ähnlich indifferent gegenüber (permissiver Konsens).

Als Vereinigung von gleichrangigen Partnern über fast ein halbes Jahrtausend ist die Hanse ein bedeutendes Beispiel für das Prinzip der erfolgreichen Konsensbildung in einem ansonsten hierarchisch strukturierten Europa und damit auch ein Beispiel für die Elastizität eines Verbandes, der sich beständig an sich stetig verändernde machtpolitische und wirtschaftspolitische Strukturen anpassen musste, um seinen weiträumigen Handel und die jeweils unterschiedliche relative Autonomie seiner Mitgliedsstädte über dieses halbe Jahrtausend aufrecht zu erhalten. Das geschah in der Regel im Rahmen einer Friedenspolitik, die auf diplomatischem Weg die Lösung von Konflikten herbeiführte, und einer Wirtschaftspolitik, die auf einem Netzwerk von (Familien-)Unternehmen mit ausgeprägter Kooperation beruhte, das von Seiten der Städte mit einer Vielzahl infrastruktureller Maßnahmen unterstützt wurde. Hinzu kommt ein weiterer Aspekt, 
der im vorliegenden Beitrag nicht behandelt werden konnte: Die republikanisch-oligarchische Staatsform überlebte in dem adlig-hierarchisch geprägten Europa nur in den drei Hansestädten Lübeck, Hamburg und Bremen sowie in den verfassungsrechtlich ähnlich gestalteten Ländern der Schweiz ${ }^{145}$ und - cum grano salis - der Niederlande - und zwar durchgehend vom 13. bis ins 21 . Jahrhundert.

Ergänzen wir noch, dass sich die Bedeutung der Wirtschaft als Basis kulturellen Austausches in dem ehemaligen hansischen Wirtschaftsraum noch heute in so unterschiedlichen Erscheinungsformen wie Stadtanlagen, Backsteingotik, Sprachverwandtschaft, Buchdruck, Geldwesen, Kunst und Religion zeigt, so ist es dieses Erbe in Wirtschaft, Verfassung, Recht und Kultur Wert, in Europa als wesentlicher Bestandteil des Zusammenwachsens der Regionen und Völker dieses Kontinents weiterhin erinnert zu werden. Oder etwas zeit- und standesgemäßer: Die historisch-wissenschaftliche Erforschung der Transferprozesse, die den ,Kommunikationsraum Europa“ durch „Bildung, Beeinflussung und Verlagerung der Funktionsbereiche Zentrum und Peripherie" in steter Bewegung hielten und halten, verspricht Aufschlüsse darüber, wie dieses Europa funktionierte und funktioniert. ${ }^{146}$ In diesem Rahmen haben der Vergleich, nicht die Gleichsetzung, der Hanse mit der Europäischen Union und der Vergleich des Zeitalters der Hanse mit dem der Globalisierung ihre, lebensweltliche ${ }^{6 / 47}$ und ihre wissenschaftliche Berechtigung.

\footnotetext{
${ }^{145}$ Tamara MÜNGER, Hanse und Eidgenossenschafı - zwei mittelalterliche Gemeinschaften im Vergleich, in: HGhll. 119, 2001, S. 5-48: s. auch Eva-Maria DisTler. Städtebünde im deutschen Spätmittelalter. Eine rechtshistorische Untersuchung zu Begriff, Verfassung und Funktion (Studien zur europäischen Rechtsgeschichte, Bd. 207), Frankfurt am Main 2006. die auf S. 49-68 unter der Überschrift „Ausgrenzungen“ die beiden Sonderfälle der schweizerischen Eidgenossenschaft und der Hanse behandelt.

${ }^{146}$ So das Fazit des sehr lesenswerten Beitrags von OSCHEMA, Europa in der mediävistischen Forschung (wie Anm. 26), S. $31 \mathrm{f}$.

${ }^{147}$ Siehe oben Anm. 46.
} 